University of Louisville

ThinkIR: The University of Louisville's Institutional Repository

Electronic Theses and Dissertations

$8-2020$

\title{
Soluble epoxide hydrolase inhibition: a novel therapeutic strategy in alcoholic liver disease.
}

Jeffrey Barr Warner

University of Louisville

Follow this and additional works at: https://ir.library.louisville.edu/etd

Part of the Medical Pharmacology Commons

\section{Recommended Citation}

Warner, Jeffrey Barr, "Soluble epoxide hydrolase inhibition: a novel therapeutic strategy in alcoholic liver disease." (2020). Electronic Theses and Dissertations. Paper 3481.

https://doi.org/10.18297/etd/3481

This Master's Thesis is brought to you for free and open access by ThinkIR: The University of Louisville's Institutional Repository. It has been accepted for inclusion in Electronic Theses and Dissertations by an authorized administrator of ThinkIR: The University of Louisville's Institutional Repository. This title appears here courtesy of the author, who has retained all other copyrights. For more information, please contact thinkir@louisville.edu. 
SOLUBLE EPOXIDE HYDROLASE INHIBITION: A NOVEL THERAPEUTIC STRATEGY IN ALCOHOLIC LIVER DISEASE

\author{
By \\ Jeffrey Barr Warner \\ B.S., Murray State University, 2017 \\ A Thesis \\ Submitted to the Faculty of the \\ School of Medicine of the University of Louisville \\ in Partial Fulfillment of the Requirements \\ for the Degree of \\ Master of Science \\ in Pharmacology and Toxicology \\ Department of Pharmacology and Toxicology \\ University of Louisville \\ Louisville, Kentucky
}

August 2020 

SOLUBLE EPOXIDE HYDROLASE INHIBITION: A NOVEL THERAPEUTIC STRATEGY IN ALCOHOLIC LIVER DISEASE

\author{
By \\ Jeffrey Warner
}

B.S. Murray State University, 2017

A Thesis Approved on

July $9^{\text {th }}, 2020$

By the following Thesis Committee:

Irina Kirpich, PhD, MPH

Walter Watson, $\mathrm{PhD}$

Kyung Hong, $\mathrm{PhD}$

Swati Joshi-Barve, $\mathrm{PhD}$

Barbara Clark, PhD 


\section{DEDICATION}

This thesis is dedicated to Dennis and Susan Warner for offering me invaluable educational opportunities and support. Thank you for encouraging me to never stop asking questions. 


\section{ACKNOWLEDGMENTS}

I would like to thank my $\mathrm{PhD}$ mentor, Dr. Irina Kirpich for her guidance and patience in my post-baccalaureate and pre-doctoral training. She has encouraged and supported me every step of the way, and continually challenges me to achieve my best. Dr. Kirpich takes every opportunity to show off my accomplishments to others. For these reasons and others, I am ever grateful for her mentorship. 


\title{
ABSTRACT \\ SOLUBLE EPOXIDE HYDROLASE INHIBITION: A NOVEL THERAPEUTIC STRATEGY IN ALCOHOLIC LIVER DISEASE
}

\author{
Jeffrey B. Warner
}

July $9^{\text {th }}, 2020$

Emerging evidence suggests that soluble epoxide hydrolase ( $\mathrm{sEH})$ inhibition is a valuable therapeutic strategy for the treatment of numerous diseases. sEH rapidly degrades cytochrome P450-produced epoxygenated lipids (epoxy-fatty acids, epFAs), which generally exert beneficial effects on several cellular processes. sEH hydrolysis of epoxyfatty acids produces dihydroxy-fatty acids which are typically less biologically active than their parent epoxide. sEH inhibition has shown efficacy in treating numerous pathologies associated with non-alcoholic liver disease, yet no efforts to date have tested the efficacy of sEH inhibition in alcoholic liver disease (ALD). Herein, we measured the levels of sEH expression and epFAs in human ALD, and assessed the efficacy of the sEH inhibitor tTUCB in multiple pre-clinical mouse models of ALD. Mice exposed to ethanol but treated with t-TUCB had decreased liver injury, inflammation, and endoplasmic reticulum (ER) stress compared to controls, an observation that was reproduced in whole-body $\mathrm{sEH}$ knockout mice. In vitro, individual epFAs (17,18-EpETE and 19,20-EpDPA) prevented hepatocyte apoptosis/ER stress and endotoxin-induced pro-inflammatory cytokine production in macrophages. These results suggest the ability of sEH inhibition to prevent 
alcohol-associated liver injury, inflammation, and ER stress, that is potentially mediated by specific epFAs. Future work will determine the efficacy of sEH inhibition in a treatment paradigm of sEH inhibitor administration and further elucidate molecular mechanisms. 


\section{TABLE OF CONTENTS}

ACKNOWLEDGEMENTS

ABSTRACT $\quad$ V

LIST OF FIGURES Ix

CHAPTER 1: INTRODUCTION 1

Epoxy-Fatty Acids and Soluble Epoxide Hydrolase Activity/Inhibition 1

sEH Inhibition in Metabolic Syndrome, Non-Alcoholic Fatty Liver

Disease, and Non-Alcoholic Steatohepatitis $\quad 7$

sEH Inhibition in Hepatic Fibrosis and Portal Hypertension 11

sEH Inhibition in Sepsis Models 14

Molecular Mechanisms of sEHI-Mediated Protection against

$\begin{array}{ll}\text { Liver Diseases } & 15\end{array}$

$\begin{array}{ll}\text { Knowledge Gaps } & 19\end{array}$

$\begin{array}{ll}\text { sEH Inhibition and ALD } & 21\end{array}$

CHAPTER 2: MATERIALS AND METHODS 23

$\begin{array}{ll}\text { Experimental Animals } & 23\end{array}$

$\begin{array}{ll}\text { Experimental Design } & 23\end{array}$

$\begin{array}{ll}\text { Assessment of Liver Damage } & 24\end{array}$

$\begin{array}{ll}\text { qPCR } & 25\end{array}$

$\begin{array}{ll}\text { Western Blotting } & 26\end{array}$

Plasma t-TUCB Analysis $\quad 26$

$\begin{array}{ll}\text { Liver triglycerides } & 27\end{array}$

Targeted Lipidomic Analysis of epFAs in Human and Mouse

$\begin{array}{ll}\text { Liver Tissue } & 27\end{array}$ 
$\begin{array}{ll}\text { Cell Culture } & 27\end{array}$

$\begin{array}{ll}\text { Statistical Analysis } & 28\end{array}$

CHAPTER 3: RESULTS 29

Lipidomic Analysis of Human Liver Tissue 29

sEH Inhibition Improved Liver Injury in Two Mouse ALD Models 30

t-TUCB did not Affect Hepatic Steatosis 33

sEH Inhibition Attenuated Chronic EtOH-Associated Liver Inflammation 34

sEH Inhibition Attenuated Chronic EtOH-Associated Liver $\begin{array}{ll}\text { ER Stress } & 35\end{array}$

Genetic Ablation of sEH Similarly Decreased Liver Injury and Inflammation 37

epFAs Prevented Hepatocyte Apoptosis and MacrophageMediated Cytokine Production 38

CHAPTER 4: DISCUSSION 41

CHAPTER 5: SUMMARY AND CONCLUSIONS 46

REFERENCES 49

CURRICULUM VITAE 


\section{LIST OF FIGURES}

FIGURE 1. Endogenous role of soluble epoxide hydrolase 2

FIGURE 2. Commonly used soluble epoxide hydrolase inhibitors 4

FIGURE 3. sEH inhibition in liver diseases: knowns and unknowns 21

$\begin{array}{ll}\text { FIGURE 4. Feeding model schemes } & 24\end{array}$

FIGURE 5. Liver tissue from human ALD patients has decreased $\begin{array}{ll}\text { levels of epFAs } & 30\end{array}$

FIGURE 6. sEH inhibition decreases liver injury in multiple mouse models of ALD $\quad 32$

FIGURE 7. sEH inhibition does not affect hepatic steatosis 33

FIGURE 8. sEH inhibition improves chronic EtOH-associated liver inflammation

FIGURE 9. sEH inhibition improves chronic EtOH-associated liver ER stress

FIGURE 10. Genetic ablation of sEH attenuates liver injury $\begin{array}{ll}\text { and inflammation } & 38\end{array}$

FIGURE 11. 19,20-EpDPA prevents hepatocyte cell death 39

FIGURE 12. EpFAs prevent macrophage-mediated pro-inflammatory $\begin{array}{ll}\text { cytokine release } & 40\end{array}$

$\begin{array}{ll}\text { FIGURE 13. Summary figure } & 47\end{array}$ 


\section{CHAPTER 1}

\section{INTRODUCTION}

\section{Epoxy-Fatty Acids and Soluble Epoxide Hydrolase Activity/Inhibition}

Since their discovery in the 1970s, mammalian epoxide hydrolases (EHs) have become an increasingly popular focus of research due to their role in disease pathology [1, 2]. This family of proteins consists of four enzymes encoded by genes Ephxl-4, where Ephx1 and Ephx2 encode microsomal and soluble EHs (mEH and sEH, respectively), and Ephx3 and Ephx4 encode EH3 and EH4, which are not well characterized. EHs are expressed across all domains of life, including both mammalian and non-mammalian animals [3], including insects, frogs, fish, nematodes [4], and plants, protists [5], fungi, and several phyla of bacteria (e.g., actinobacteria, proteobacteria, firmicutes, and others [6]). EHs catalyze the hydrolysis of epoxides by the addition of water to form vicinal diols. Importantly, substrate specificity differs between EHs: $\mathrm{mEH}$ generally acts upon toxic xenobiotic epoxides, whereas sEH generally acts upon endogenous lipid epoxides [1]. An important class of sEH substrates are the cytochrome P450 (CYP450) monooxygenase products of omega-3 and omega-6 polyunsaturated fatty acids (PUFAs), herein referred to as epoxy-fatty acids (epFAs). This class includes epoxyeicosatrienoic acids (EETs, products of arachidonic acid [AA]), epoxyoctadecenoic acids (EpOMEs, products of linoleic acid [LA]), epoxyeicosatetraenoic acids (EpEETs or EEQs, products of eicosapentaenoic acid [EPA]), and epoxydocosapentaenoic acids (EpDPAs or EDPs, products of docosahexaenoic acid [DHA]) (Figure 1). The CYP2C and CYP2J subfamilies are primarily responsible for the production of these epFAs [7], which generally exert beneficial effects on a number of cellular processes. For example, epFAs can be anti- 


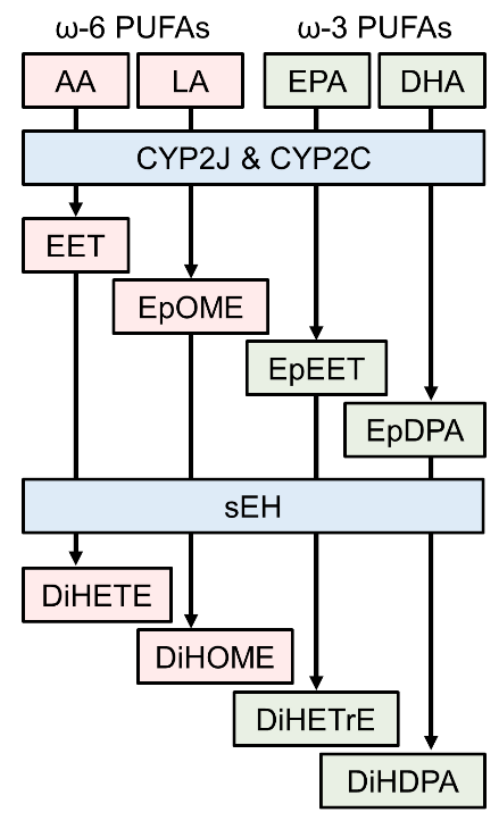

Figure 1. Endogenous role of soluble epoxide hydrolase. Cytochrome P450 monooxygenases catalyze the addition of an epoxide ring to polyunsaturated fatty acids, including omega-6 arachidonic and linoleic acids (AA and LA, respectively) and omega-3 eicosapentaenoic and docosahexaenoic acids (EPA and DHA, respectively). Soluble epoxide hydrolase $(\mathrm{sEH})$ rapidly degrades these beneficial epFAs to their inactive, less active, or deleterious cognate dihydroxylated fatty acids. EET, epoxyeicosatrienoic acid; EpOME, epoxyoctadecenoic acid; EpEET, epoxyeicosatetraenoic acid; EpDPA, epoxydocosapentaenoic acid; DiHETE, dihydroxyeicosatrienoic acid; DiHOME, dihydroxyoctadecenoic acid; DiHETrE, dihydroxyeicosatetraenoic acid; DiHDPA, dihydoxydocosapentaenoic acid.

inflammatory [8-10] and anti-fibrotic [11], and can promote the resolution of inflammation [12] and tissue regeneration [13]. However, not all epFAs are beneficial - for example, LA (an omega-6 fatty acid)-derived 9,10-EpOME and 12,13-EpOME are associated with respiratory distress and interfere with neutrophil function following infection [14].

The potent biological effects of epFAs are abrogated due to their rapid hydrolysis by $\mathrm{EHs}$ - particularly $\mathrm{sEH}$, the main $\mathrm{EH}$ responsible for endogenous lipid epoxide degradation [15]. sEH is a dual function enzyme with a C-terminal hydrolase domain and N-terminal phosphatase domain. The role of the phosphatase domain is not well 
characterized [16], but hydrolase domain-mediated breakdown of epFAs is a well-known process considered to deactivate epFAs. Indeed, dihydroxyeicosanoid products of epFAs (dihydroxyFAs) are generally less biologically active, inactive, or, in some cases, deleterious [17]. Logically, preservation of epFA levels by sEH inhibition is an attractive therapeutic option. To this end, numerous sEH inhibitors (sEHIs) have been developed using various pharmacophores, and with variable dissociation constants through the nanomolar and micromolar ranges. In the last decade, the disubstituted urea pharmacophore has gained popularity because of its higher potency than the previous generation of inhibitors [18]. Compounds in this class include TPPU, TPAU, APAU, TPCU, TUPS, AUCB, and t-TUCB (see Table 2 for full chemical names and Figure 2 for chemical structures and full chemical names); these inhibitors are used commonly in experimental animal and cell culture models of various pathologies. Indeed, preclinical animal models have demonstrated the efficacy of sEHIs in the treatment of atherosclerosis $[19,20]$, kidney injury [21-24], acute lung injury [25-28], inflammatory bowel disease [2931], angiogenesis and cancer [32, 33], psychiatric and neurological disorders [34-37], sepsis [38], and more. Moreover, there are several clinical trials testing the effectiveness of sEHIs in humans. The sEHI GSK2256294 has completed a phase I clinical trial to determine its safety, pharmacokinetics, and efficacy in treating glucose intolerance (ClinicalTrials.gov NCT03486223) and smoking-related endothelial dysfunction [39]. Another compound, AR9281, has also completed phase I clinical trials for hypertension and insulin resistance treatment (ClinicalTrials.gov NCT00847899). Another sEHI, EC5026, is under development to reduce neuropathic pain in humans (NIH NIDA 1UG3DA048767-01). 
Table 1. Abbreviations and full chemical names for commonly used sEH inhibitors.

\begin{tabular}{|c|c|}
\hline $\begin{array}{l}\text { Inhibitor } \\
\text { Abbreviation }\end{array}$ & Inhibitor Full Name \\
\hline TPPU & $\begin{array}{l}N \text {-[1-(1-Oxopropyl)-4-piperidinyl]- } N^{\prime}-[4- \\
\quad \text { (trifluoromethoxy)phenyl]-urea }\end{array}$ \\
\hline TPAU & 1-trifluoromethoxyphenyl-3-(1-acetylpiperidin-4-yl)-urea \\
\hline APAU & 1-(1-acetypiperidin-4-yl)-3-adamantanyl-urea \\
\hline TPCU & $\begin{array}{l}\text { 1-(1-(Cyclopropanecarbonyl) piperidin-4-yl)-3-(4- } \\
\text { (trifluoromethoxy) phenyl)-urea }\end{array}$ \\
\hline TUPS & $\begin{array}{l}\text { 1-(1-methanesulfonyl-piperidin-4-yl)-3-(4-trifluoromethoxy- } \\
\text { phenyl)-urea }\end{array}$ \\
\hline $\mathrm{t}-\mathrm{AUCB}$ & $\begin{array}{c}\text { trans-4-[4-(3-Adamantan-1-yl-ureido)-cyclohexyloxy]- } \\
\text { benzoic acid }\end{array}$ \\
\hline $\mathrm{t}$-TUCB & $\begin{array}{c}\text { 4-[[trans-4-[[[[4-Trifluoromethoxy)phenyl]amino]carbonyl]- } \\
\text { amino]cyclohexyl]oxy]-benzoic acid }\end{array}$ \\
\hline
\end{tabular}

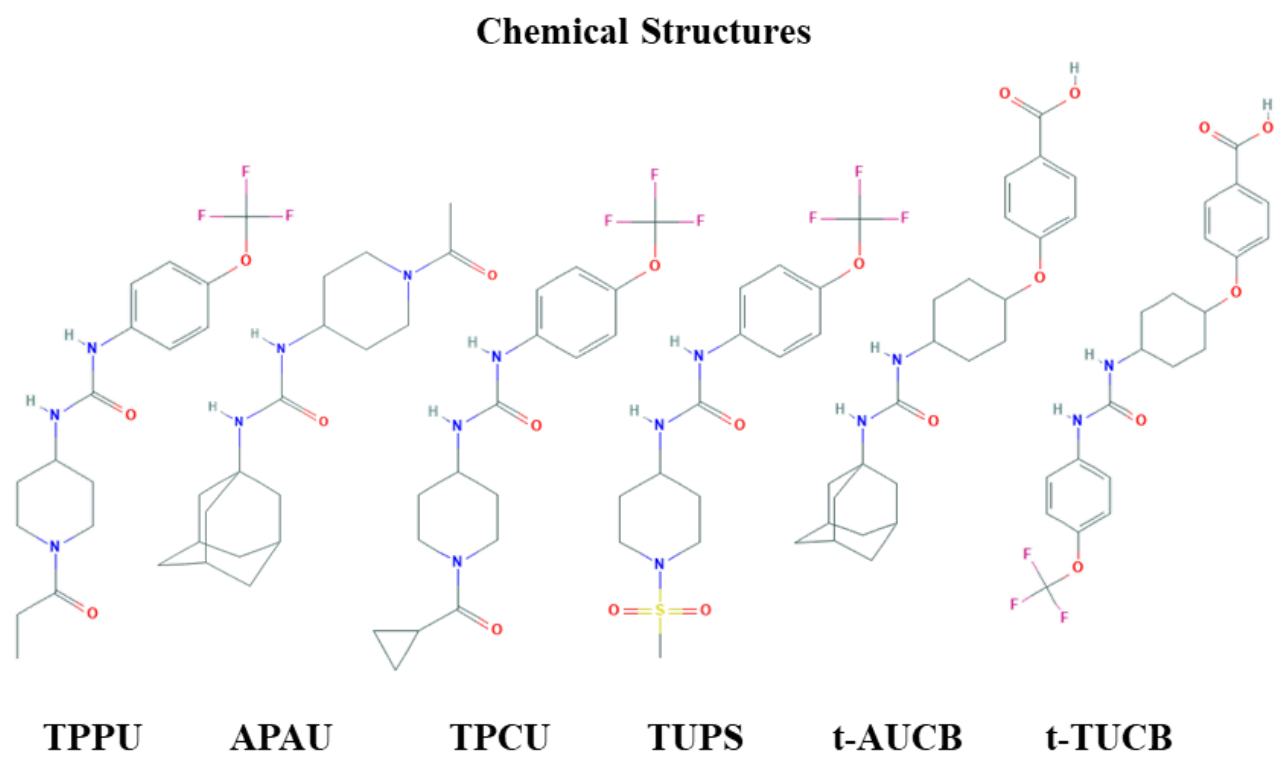

Figure 2. Chemical structures for representative inhibitors. Chemical structures were reproduced from the public PubChem database (pubchem.ncbi.nlm.nih.gov). 
There is accumulating evidence that $\mathrm{sEH}$ expression is induced in many liver pathologies, including non-alcoholic fatty liver disease (NAFLD), non-alcoholic steatohepatitis (NASH), liver fibrosis, and portal hypertension (PTH) [40-44]. While much effort has been expended to develop treatments, these liver diseases remain a global health burden. For example, global prevalence of NAFLD is estimated at roughly one in four [45]. Preservation of the remaining epFA pool by sEH inhibition represents an exciting novel therapeutic strategy with low adverse effects [46] to address this health crisis. The following sections summarize the novel field of $\mathrm{sEH}$ inhibition in liver diseases by analyzing preclinical studies in several liver pathologies including NAFLD and associated metabolic disorders, NASH, and PTH. The reader is encouraged to consult Table 2 for categorical information on each key study reviewed.

Table 2. Summary of studies investigating the role of sEH in liver diseases. Listed are studies cited in the review, along with details of the experimental design (model, species, and sEHI used) and a brief description of the results and mechanism, if available. Changes in sEH expression or activity are noted in the results column, where available.

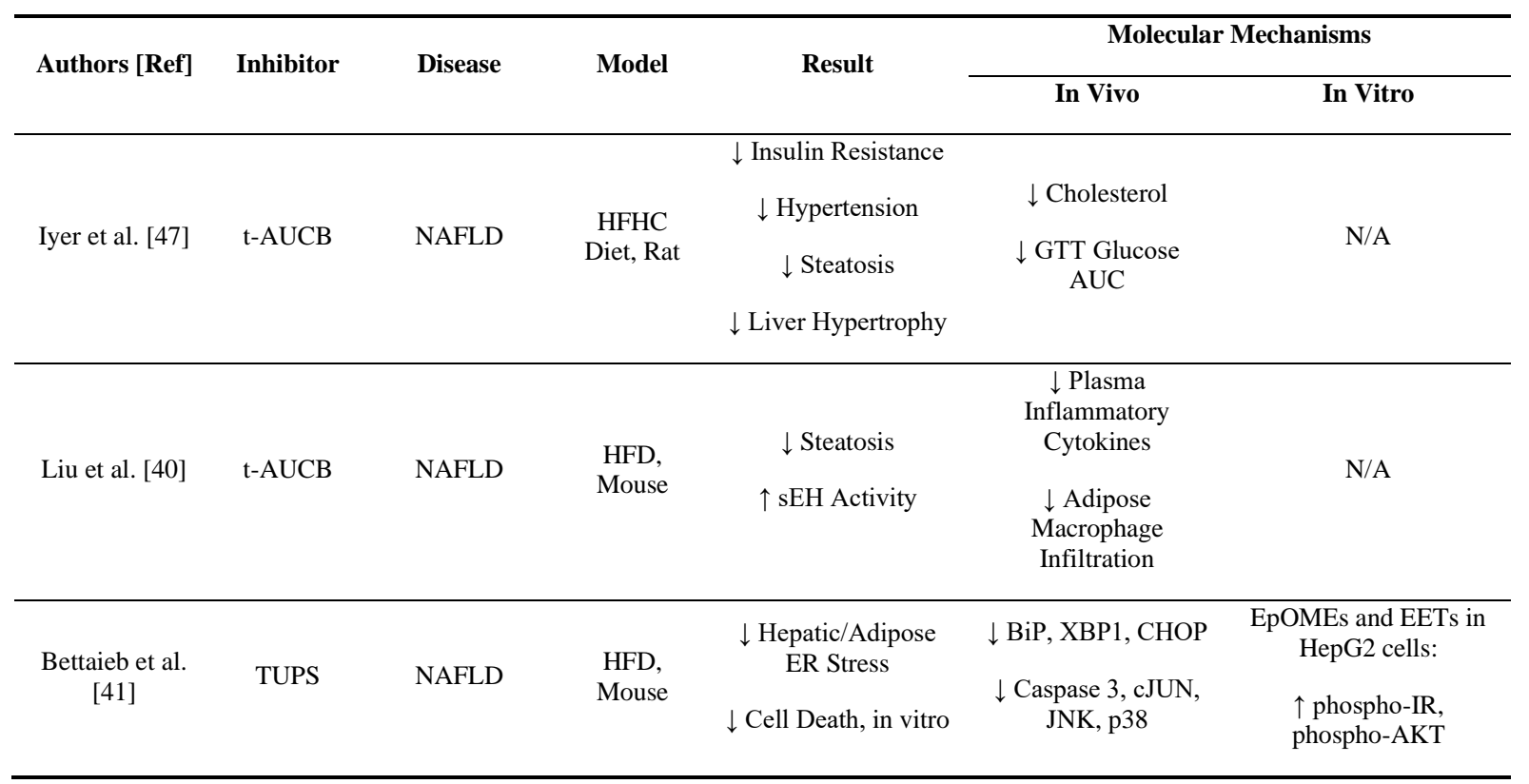




\begin{tabular}{|c|c|c|c|c|c|c|}
\hline & & & & $\begin{array}{l}\uparrow \text { Insulin Signaling, } \\
\text { in vitro } \\
\uparrow \text { sEH Protein }\end{array}$ & & \\
\hline $\begin{array}{l}\text { Lopez-Vicario } \\
\text { et al. [42] }\end{array}$ & t-TUCB & NAFLD & $\begin{array}{l}\text { HFD, } \\
\text { Mouse }\end{array}$ & $\begin{array}{c}\uparrow \text { Brown Fat } \\
\uparrow \text { Hepatic } \\
\text { Autophagy } \\
\downarrow \text { Steatosis } \\
\uparrow \mathrm{sEH} \text { Protein }\end{array}$ & $\begin{array}{c}\uparrow \text { IL10, RELM } \alpha, \\
\text { CD206, } \\
\text { MGL1 } \\
\uparrow \text { M2 Polarization }\end{array}$ & $\begin{array}{c}\text { 14,15-EET, 19,20- } \\
\text { EpDPA, and 17,18- } \\
\text { EpETE in Primary } \\
\text { Hepatocytes: } \\
\downarrow \text { Lipid accumulation } \\
\downarrow \text { phospho-eIF2 } \alpha, \\
\text { phospho-IRE1 } \alpha \\
\uparrow \text { LC3II:LC3I ratio }\end{array}$ \\
\hline Sun et al. [43] & PTUPB & NAFLD & $\begin{array}{l}\text { HFD, } \\
\text { Mouse }\end{array}$ & $\begin{array}{c}\downarrow \text { Body/Liver } \\
\text { Weight } \\
\downarrow \begin{array}{c}\text { Liver Injury and } \\
\text { Steatosis }\end{array} \\
\downarrow \text { Fibrosis } \\
\downarrow \text { Inflammation } \\
\uparrow \text { sEH Protein }\end{array}$ & $\begin{array}{c}\downarrow \text { NLRP3 } \\
\text { Inflammasome } \\
\text { Activation } \\
\downarrow \text { Inflammatory } \\
\text { Cytokines } \\
\downarrow \text { COX2 Expression }\end{array}$ & N/A \\
\hline Chen et al. [48] & N/A & NAFLD & $\begin{array}{l}\text { HFD, } \\
\text { Mouse }\end{array}$ & $\begin{array}{c}\downarrow \text { Steatosis } \\
\downarrow \text { Inflammation } \\
\downarrow \text { Oxidative Stress }\end{array}$ & $\begin{array}{c}\downarrow \text { NFאB } \\
\downarrow \text { JNK } \\
\uparrow \mathrm{SOD}, \mathrm{GPX}\end{array}$ & $\begin{array}{c}\text { 14,15-EET in HepG2 } \\
\text { cells: } \\
\downarrow \text { NFאB, TNF } \alpha, \text { IL1 } \beta, \\
\text { IL6 } \\
\text { 14,15-EET in } \\
\text { RAW264.7 cells: } \\
\downarrow \text { TNF } \alpha, \text { IL1 } \beta, \text { IL6 }\end{array}$ \\
\hline Yao et al. [49] & TPPU & NAFLD & $\begin{array}{l}\text { HMD, } \\
\text { Mouse }\end{array}$ & $\begin{array}{c}\downarrow \text { Steatosis } \\
\uparrow \mathrm{sEH} \text { Protein }\end{array}$ & $\begin{array}{c}\uparrow \text { Fatty Acid } \beta- \\
\text { Oxidation Genes } \\
\uparrow \text { PPAR } \alpha \text { Activation }\end{array}$ & $\begin{array}{c}\text { sEH Inhibition and } \\
\text { 11,12-EET in Primary } \\
\text { Hepatocytes: } \\
\uparrow \text { PPAR } \alpha \text { Activation }\end{array}$ \\
\hline $\begin{array}{c}\text { Mangels et al. } \\
\text { [50] }\end{array}$ & t-AUCB & $\begin{array}{l}\text { Metabolic } \\
\text { Syndrome }\end{array}$ & Mouse & $\downarrow$ Cholesterol & $\begin{array}{c}\uparrow \text { AMPK Activation } \\
\downarrow \text { SREBP1 } \\
\downarrow \text { HMG CoA } \\
\text { Reductase }\end{array}$ & $\begin{array}{c}12,13 \text {-EpOME in vitro: } \\
\uparrow \text { phospho-AMPK } \\
\downarrow \text { HMG CoA } \\
\text { Reductase }\end{array}$ \\
\hline $\begin{array}{c}\text { Harris et al. } \\
\text { [51] }\end{array}$ & TPPU & Liver Fibrosis & $\begin{array}{l}\mathrm{CCl}_{4} \text {, } \\
\text { Mouse }\end{array}$ & $\begin{array}{l}\downarrow \text { Fibrosis } \\
\downarrow \text { ER Stress }\end{array}$ & $\begin{array}{c}\uparrow \text { Metalloproteases } \\
\downarrow \text { Col1a2/Col3a1 } \\
\text { mRNA } \\
\downarrow \text { JNK, Caspase } 3\end{array}$ & N/A \\
\hline $\begin{array}{l}\text { Zhang et al. } \\
\text { [44] }\end{array}$ & t-TUCB & Liver Fibrosis & $\mathrm{CCl}_{4}$, Rat & $\begin{array}{c}\downarrow \text { Fibrosis } \\
\downarrow \text { Portal } \\
\text { Hypertension } \\
\downarrow \text { Inflammation } \\
\downarrow \text { Oxidative Stress } \\
\uparrow \text { sEH Protein }\end{array}$ & $\begin{array}{c}\downarrow \mathrm{TGFb} \\
\downarrow \text { Smad } \\
\downarrow \text { NFkB } \\
\uparrow \text { Metalloproteases } \\
\uparrow \mathrm{SOD}, \mathrm{GSH}\end{array}$ & N/A \\
\hline
\end{tabular}




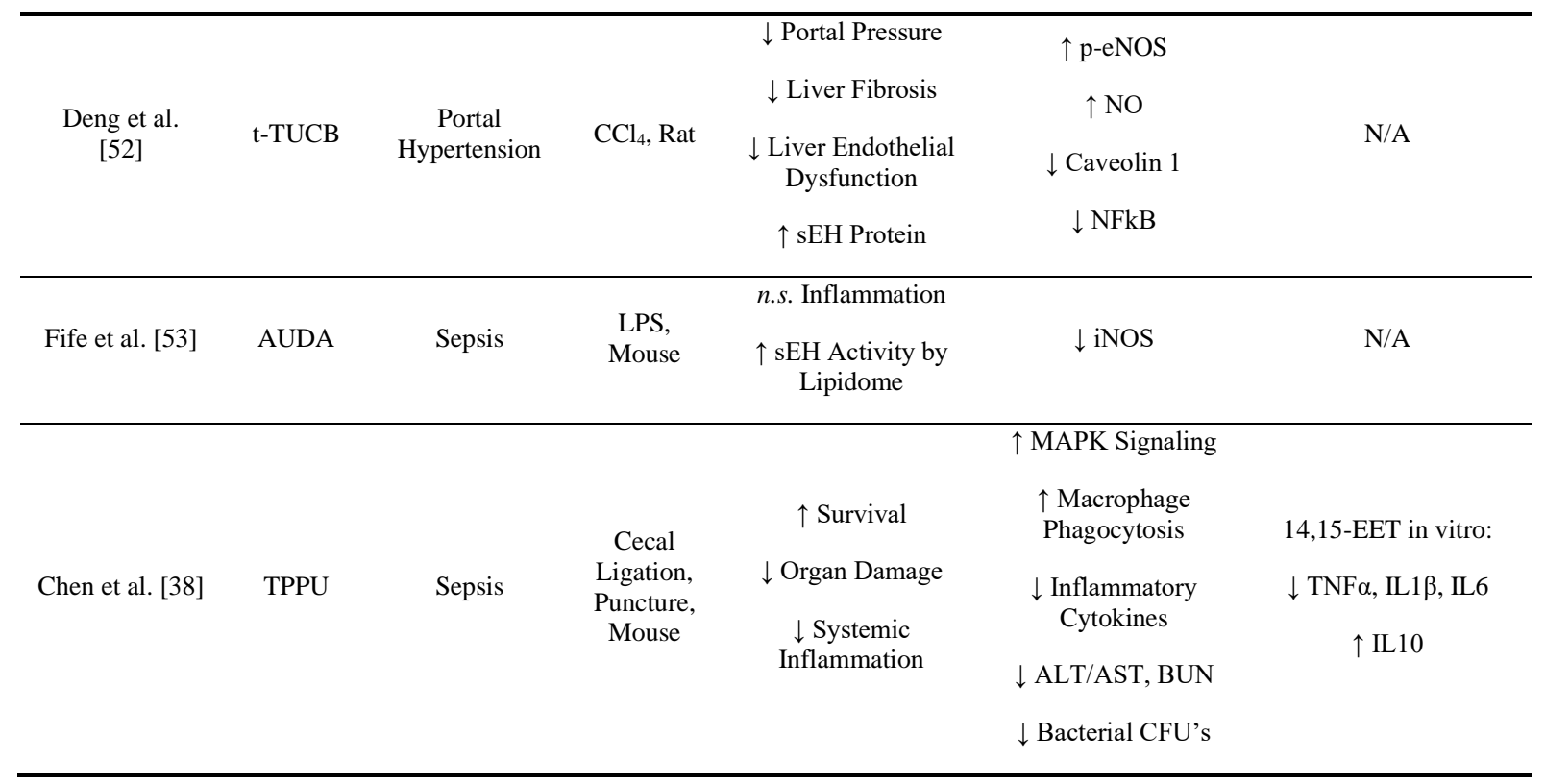

\section{sEH Inhibition in Metabolic Syndrome and Non-Alcoholic Fatty Liver Disease}

Epidemiological data show a strong association between NAFLD and metabolic syndrome, but the connection between the two is more than correlative: insulin resistance and lipid accumulation associated with metabolic disorder contribute directly to NAFLD pathogenesis [54]. For example, hepatic steatosis, an early manifestation of NAFLD, is the result of accumulation of "benign" lipid vesicles in the liver without significant inflammation or cell death and is common in metabolic syndrome patients [55]. From here, a minority of patients with NAFLD develop progressive NASH, wherein steatosis is accompanied by hepatic inflammation (primarily mediated by neutrophils and macrophages/recruited monocytes) and hepatocyte death [56]. NAFLD and NASH patients may or may not develop accompanying fibrosis, a complication that increases mortality [57]. However, the highest morbidity and mortality in non-alcoholic liver disease patients is not due to end-stage liver complications, but rather due to associated cardiovascular disease and cancer [58]. 
There are several pre-clinical studies demonstrating beneficial effects of sEH inhibition in NAFLD and associated metabolic abnormalities. A report by Iyer et al. investigated the efficacy of sEH inhibition in metabolic syndrome using male Wistar rats fed a high carbohydrate, high fat (HCHF) diet ad libitum with or without the sEHI t-AUCB administered in the drinking water [47]. Compared to HCHF controls, HCHF rats treated with t-AUCB had significant improvements in metabolic endpoints including plasma lipid levels and insulin sensitivity. The study also investigated pathological changes related specifically to the liver, demonstrating that sEH inhibition by t-AUCB attenuated HCHF diet-induced liver hypertrophy, steatosis, and injury (confirmed by decreased lactate dehydrogenase and aspartate aminotransferase levels [LDH and AST, respectively], plasma biomarkers of liver injury). However, they reported no protection against HCHF diet-induced liver immune cell infiltration. This report on the pathogenic role of sEH in NAFLD has been corroborated by a host of other studies. For example, Liu et al. used an eight-week high fat diet (HFD) feeding to induce NAFLD in C57BL/6 mice, then administered t-AUCB for four additional weeks (i.e. a 'treatment' paradigm) [40]. Wholebody sEH knockout $\left(E p h x 2^{--}\right)$mice were also fed a control or HFD. Compared to controls, HFD + t-AUCB mice had decreased steatosis as shown by liver hematoxylin \& eosin (H\&E) staining and reduced liver triglyceride content. Unlike Iyer et al., Liu et al. demonstrated a marked improvement in liver inflammation in HFD mice given t-AUCB or in Ephx $2^{-/-}$mice. Specifically, decreased macrophage accumulation as determined by F4/80 immunohistochemistry and decreased mRNA expression of numerous pro-inflammatory cytokines (e.g. TNF $\alpha$, IL-6, MCP-1, IFN $\gamma$ ) were observed. In this study, t-AUCB was also administered in a prevention paradigm, where the inhibitor was added to the drinking water 
prior to the animals being placed on a longer term 16-week HFD feeding protocol. In this paradigm, the NAFLD phenotype was similarly abrogated - decreased liver organ hypertrophy, decreased steatosis and liver/plasma triglycerides, and decreased inflammatory cytokine expression were reported in this model. Further, markers of inflammatory pathway activation (JNK and p38) were reduced. Conversely, when mice were injected with adenoviruses encoding human sEH, metabolic syndrome was exacerbated - liver/plasma lipids were increased, pro-inflammatory cytokine production was increased, and JNK and p38 proteins were increased. sEH inhibition or deletion also caused a reduction in HFD-induced adipose tissue inflammation, suggesting a role for the adipose-liver axis in sEH-mediated liver pathology. A study by Yao et al. also supports a pathogenic role for sEH in NAFLD [49]. Here, a high methionine diet (HMD) was used to induce hyperhomocysteinemia (HHcy) and hepatic steatosis. HHcy is prevalent in individuals with NAFLD and is considered a significant risk factor $[59,60]$. In mice fed an HMD, sEH inhibition by TPPU ameliorated hepatic steatosis as shown by liver H\&E staining and decreased hepatic triglycerides compared to controls, likely due to an increase in the expression of $\beta$-oxidation genes (Cpt1 $\alpha$, Acoxl, and Mcad).

Mechanistically, evidence generated by Sun et al. suggests that sEH inhibition may reduce hepatic inflammation by blocking inflammasome activation [43]. While the inflammasome is a key protein complex that regulates the adaptive response of the liver to pathogenic challenge, evidence also suggests a deleterious role in numerous liver diseases [61]. Sun et al. demonstrated that administration of 4-(5-phenyl-3-\{3-[3-(4trifluoromethyl-phenyl)-ureido]-propyl\} $S$-pyrazol-1-yl) benzenesulfonamide (PTUPB) reduced inflammasome activation, as evidenced by a decrease in Nlrp3/NLRP3 and Asc 
expression, compared to HFD-fed mice without PTUPB. HFD-induced expression of downstream inflammasome targets pro-caspase 1 , pro-IL1 $\beta$, pro-IL18, and caspase 1 p10 were also decreased by PTUPB [43]. Additionally, administration of PTUPB reduced expression of hepatic pro-inflammatory cytokines TNF $\alpha, \mathrm{MCP} 1$, and IL-6. It should be mentioned that PTUPB is a dual inhibitor of both sEH and cyclooxygenase 2, meaning future research may be needed to confirm the role of sEH specifically in inflammasome activation.

Hepatic endoplasmic reticulum (ER) stress is a known cellular consequence of NAFLD and metabolic syndrome. During ER stress, accumulation of unfolded proteins in the ER lumen activates the unfolded protein response (UPR), a signaling pathway which acts to either mitigate the burden of unfolded proteins or trigger apoptosis [62]. ER stress is both a consequence and a driver of liver disease, due to the UPR's ability to trigger inflammation, inflammasome activation, and hepatocyte death [63]. Bettabieb et al.

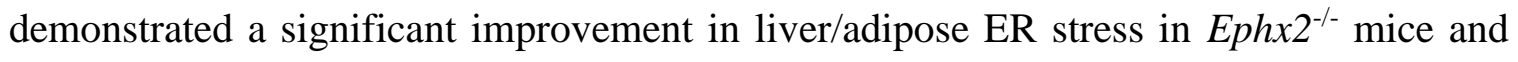
wild-type (WT) mice administered TUPS [41]. Specifically, HFD-induced mRNA expression of BiP, the ER lumen unfolded protein 'sensor', was decreased by sEH inhibition or deletion, as was activation of PERK, IRE1 $\alpha$, and ATF6, the three ER membrane-bound proteins that activate each of the three branches of the UPR. Consequently, expression of downstream effectors of these three branches (e.g. XBP1 splicing, GADD34, and phopho-eIF2 $\alpha$ ) was also decreased at the protein level. Importantly, protein expression of the pro-apoptotic transcription factor $\mathrm{CHOP}$, which lies downstream of all three branches of the UPR, was attenuated as well, indicating the pathogenic role of sEH in nearly every step of the UPR. 
Lopez-Vicario et al. further corroborated the ability of sEH inhibition to attenuate hepatic steatosis and inflammation (e.g. decreased macrophage infiltration, chemokine and pro-inflammatory cytokine production, and increased expression of the pro-resolution cytokine IL10) [42]. The ER stress associated with NAFLD/metabolic syndrome was also attenuated by sEH inhibition in this study as demonstrated by decreased protein levels of phosphorylated IRE1 $\alpha$ and eIF2 $\alpha$ (which lies downstream of PERK), thereby corroborating the protection against ER stress previously shown by Bettabieb et al. with a different sEHI. One potential contributor to this reduced ER stress is autophagy, a homeostatic process that selectively degrades damaged organelles by engulfing and targeting them for lysosomal degradation. Autophagy plays a critical role in liver health by degrading lipid droplets (lipophagy), glycogen granules (glycophagy), mitochondria and peroxisomes to regulate metabolism, and importantly, portions of stressed ER (reticulophagy/ER-phagy) [64, 65]. In numerous liver diseases (including NAFLD/metabolic syndrome, ALD, viral hepatitis, hepatocellular carcinoma [HCC], and others), autophagy is dysregulated, leading to metabolic imbalance and an inability to eliminate damaged cellular components/organelles [66]. Lopez-Vicario et al. demonstrated that sEH inhibition rescued autophagy dysregulation in a HFD mouse model of NAFLD using the sEHI t-TUCB [42]. Specifically, protein expression of autophagy-related indicators Atg12-Atg5 (a protein complex) and LC3II were decreased with HFD feeding but significantly rescued with tTUCB.

\section{sEH Inhibition in Hepatic Fibrosis and Portal Hypertension}

Liver fibrosis is a pathological feature of multiple liver diseases, including NASH, severe ALD, viral hepatitis, and cholestatic liver disease. Progressive fibrosis ultimately 
leads to liver cirrhosis and subsequent liver failure [67]. The scar tissue produced during hepatic fibrosis consists of abnormal extracellular matrix (ECM) components deposited by activated fibroblasts, typically hepatic stellate cells (HSCs) - although other fibroblasts may also play a role [68]. Importantly, fibrosis and inflammation are highly interconnected - many of the same cytokines that induce an inflammatory response (e.g. IL6, IL1 $\beta$, and TGF $\beta$ ) also activate HSCs to trigger liver fibrosis. Evidence also demonstrates that proinflammatory eicosanoids like prostaglandins and leukotrienes can promote liver fibrosis $[69,70]$, whereas epFAs have shown protection against fibrosis in several organs [71]. However, studies investigating the role of epFAs and sEH in liver fibrosis are limited.

One such report by Harris et al. demonstrated the ability of sEH inhibition to improve carbon tetrachloride $\left(\mathrm{CCl}_{4}\right)$-induced liver fibrosis in mice given TPPU in the drinking water [51]. Specifically, quantitation of liver picrosirius red staining (which binds collagen) showed significant induction of fibrosis by $\mathrm{CCl}_{4}$ and reversal back to control levels by TPPU. More mechanistically, TPPU decreased expression of genes associated with HSC activation such as Colla2, Col3a1, Itag2 (integrin a2), and Tsp2 (thrombospondin 2). TPPU also decreased both the mRNA expression and activity of matrix metalloproteases (MMPs), enzymes that positively correlate with fibrosis. $\mathrm{CCl}_{4}$ is also a potent inducer of liver inflammation and ER stress, both of which contribute to HSC activation. Harris et al. also showed that TPPU attenuated $\mathrm{CCl}_{4}$-induced markers of inflammation (Cxcr4 and $C c r 2$ ), ER stress (phospho-PERK, phospho-IRE1 $\alpha, A t f 6$, and Chop), and fibrosis ( $\operatorname{Tg} f \beta 1)$, indicating that $\mathrm{sEH}$ inhibition may inhibit liver fibrosis both directly by acting on pro-fibrotic mediators and indirectly by acting on contributing factors. Use of an additional sEHI (t-TUCB) as well as $E p h x 2^{-/-}$mice validated these results, 
suggesting a pathological role for $\mathrm{sEH}$ in liver fibrosis. Similar protection against $\mathrm{CCl}_{4}$ induced liver fibrosis and portal pressure were obtained by Zhang et al. with the sEHI tTUCB [44]. Specifically, t-TUCB decreased $\mathrm{CCl}_{4}$-induced HSC activation markers (e.g. $\operatorname{Tg} f \beta 1, \alpha S M A$ [alpha smooth muscle actin], collagens I and III, and MMPs) and markers of inflammation $(I l 1 \beta, I l 6, T n f \alpha$, and $N f \kappa b)$. In addition, readouts of oxidative stress, another cellular consequence of $\mathrm{CCl}_{4}$ administration associated with increased liver fibrosis, showed that t-TUCB decreased $\mathrm{CCl}_{4}$-induced malondialdehyde formation and rescued the $\mathrm{CCl}_{4}$-mediated loss of superoxide dismutase and glutathione.

A study by Deng et al. aimed to determine whether sEH inhibition could also ameliorate PTH in rats [52]. PTH is a complication of liver fibrosis characterized by alterations in vascular tone and increased intrahepatic vascular resistance (IHVR) which increases portal pressure and blood flow, leading to varices, ascites, hepatomegaly, and other clinical presentations [72]. This question is also of pertinent research interest due to the known role of epFAs, particularly EETs, in promoting vasodilation by activating endothelial nitric oxide synthase (eNOS) [73, 74]. Deng et al. used a $\mathrm{CCl}_{4}$ administration model of fibrosis and intrahepatic PTH which recapitulates the vascular dysfunction and structural abnormalities associated with IHVR [72]. t-TUCB administration significantly improved $\mathrm{CCl}_{4}$-induced hemodynamic deficits, significantly decreasing portal pressure, portal blood flow, and IHVR while non-significantly decreasing mean arterial pressure. In an in situ liver perfusion study to assess endothelial function, the same research group also showed t-TUCB rescued the impaired vasorelaxation caused by $\mathrm{CCl}_{4}$. This phenotype was accompanied by increased phospho-eNOS protein, nitric oxide levels, and decreased caveolin-1 protein (which reduces eNOS activity). In addition to improving hemodynamics 
and endothelial function, t-TUCB also ameliorated the underlying fibrosis/HSC activation

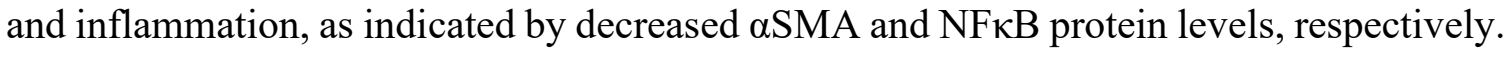
Therefore, this study suggests the ability of sEH inhibition to protect against PTH both by directly improving endothelial function and thereby hemodynamics, but also indirectly by improving the underlying fibrosis and inflammation.

\section{sEH Inhibition in Sepsis Models}

One immunological manifestation of severe liver disease is sepsis - a condition characterized by dysregulated response to inflammation following invasion of gut bacteria and associated bacterial products [75]. Like PTH, sepsis is a common a complication of cirrhosis. Cirrhosis patients are more susceptible to bacterial infection than the general population [76], and later-stage (decompensated) cirrhosis is associated with yet a higher risk [77]. Given the anti-inflammatory role of some epFAs, sEH is a logical target for treating the underlying inflammation associated with sepsis. To this end, Fife et al. investigated the ability of sEH inhibition to attenuate sepsis in a lipopolysaccharide (LPS) injection model with the sEHI AUDA administered by osmotic pump or by using Eph $x 2^{-/-}$ mice [53]. Despite the ability of sEHIs to attenuate inflammation in the previous NAFLD models [40, 42, 43], AUDA and genetic sEH deletion had limited ability to attenuate LPSinduced hepatic pro-inflammatory cytokine production (IL6, iNOS, TNF $\alpha$ ) in the early

phase of inflammation following LPS insult. By contrast, protection against LPS-induced inflammation has been demonstrated in a study by Schmelzer et al. where a higher LPS dose was used and analysis was performed at a later phase of inflammation following LPS administration [78]. 
A study by Chen et al. provides further evidence that sEHI-mediated protection against sepsis is model-dependent by showing the beneficial effects of TPPU in a surgical cecal ligation and puncture (CLP) model [38]. This polymicrobial CLP sepsis model is arguably more comparable to human sepsis than LPS injection because it causes spillage of numerous fecal bacteria into the peritoneum, whereas LPS injection only introduces a single pathogen-associated molecular pattern [79]. Chen et al. showed mice that received the sEHI TPPU by oral gavage daily for five days prior to the procedure had a $20 \%$ improvement in CLP-induced mortality compared to vehicle controls (all control mice died within the 48-hour period following the procedure). Additionally, TPPU improved signs of dysfunction in several organs, including the liver. Specifically, liver leukocyte infiltration and liver injury were significantly decreased compared to controls. Systemically, TPPU attenuated CLP-induced blood and peritoneum bacterial load and subsequently attenuated the inflammatory "cytokine storm" that follows, with decreases in systemic TNF $\alpha$, IL1 $\beta$, and IL6 levels following the surgery. Further, in a phagocytosis assay, TPPU increased RAW264.7 macrophage phagocytosis of fluorescent beads, indicating improved macrophage function. Collectively, these data suggest that sEH inhibition is a useful therapy in sepsis, but that model and phase of inflammation are critical factors determining its efficacy.

\section{Molecular Mechanisms of sEHI-Mediated Protection against Liver Diseases}

sEH may be responsible for the metabolism of some toxic xenobiotics, but the evidence reviewed here suggests a pathogenic role for sEH in liver diseases (Table 2). Indeed, many of the studies reviewed report an induction of sEH expression at the mRNA/protein level or an increase in sEH activity in different liver pathologies [40-44, 
$52,53]$. The efficacy of sEHIs generally lies in decreasing sEH activity, rather than decreasing expression of the gene/protein, although in some systems sEHIs do in fact modulate sEH protein levels. For example, Zhang et al. and Sun et al. reported that sEH inhibition by t-TUCB and PTUPB significantly reduced sEH protein in animals with PTH and NAFLD, respectively $[43,44]$. By contrast, Lopez-Vicario showed an increase in sEH protein in two different mouse genotypes after t-TUCB administration [42]. Translational curiosities aside, the protection against liver diseases afforded by sEHIs is likely due to preservation of epFAs which would otherwise be hydrolyzed by sEH. Indeed, the health benefits of epFAs derived from omega-3 and omega-6 PUFAs have long been demonstrated. In 1999, the anti-inflammatory properties of AA-derived EETs were discovered and linked to down-regulation of NFkB [8]. EETs also promote organ regeneration/compensatory growth (including regeneration of the liver), wound healing, and retina/cornea vascularization [13]. EpFAs have also been implicated in preventing inflammation and promoting the resolution of inflammation [12]. While sEH inhibition is the more logical approach pharmacologically, boosting epFA pools by increasing their synthesis rather than preventing their degradation also improves disease phenotype. Evidence shows that liver overexpression of the epFA-producing Cyp $2 j 2$ improves NAFLD endpoints like steatosis, inflammation, and oxidative stress [48].

In vitro studies suggest a link between individual epFAs and mechanisms underlying liver pathology such as lipid/cholesterol accumulation, insulin signaling, ER stress, autophagy, and inflammation. With respect to lipids and cholesterol, Mangels et al. showed a beneficial role for LA-derived 12,13-EpOME in cholesterol homeostasis in HepG2 cells [50]. In this study, 12,13-EpOME, but not 12,13-DiHOME, decreased protein 
expression of HMG CoA reductase, the rate limiting enzyme in cholesterol biosynthesis, by increasing expression of its inhibitor AMP-activated protein kinase. Lopez-Vicario et al. showed that palmitic acid (PA)-induced lipid accumulation in primary mouse hepatocytes was abrogated by AA-derived 14,15-EET, EPA-derived 17,18-EpETE, and DHA-derived 19,20-EpDPA [42]. EpFAs are also implicated in insulin signaling, another critical factor in metabolic syndrome and NAFLD. Bettabieb et al. treated HepG2 cells with unspecified EETs and EpOMEs, which enhanced basal and insulin-stimulated insulin receptor phosphorylation and protein kinase B phosphorylation (which induces glucose transport) [41]. With respect to ER stress, the same EETs and EpOMEs showed no effect on PA-induced ER stress, but interestingly, the sEH hydrolysis products (DiHETEs and DiHOMEs) exacerbated ER stress (as shown by phospho-IRE1 $\alpha$, phospho-eIF2 $\alpha$, and phospho-PERK levels) suggesting that sEHI-mediated protection may come in the form of epFA preservation or dihydroxyFA depletion [41]. Interestingly, Lopez-Vicario et al. were able to demonstrate attenuated ER stress with 14,15-EET, 17,18-EpETE, and 19,20EpDPA in primary hepatocytes. These three epoxides also increased the LC3II:LC3I protein ratio, indicating enhanced activation of autophagy. With respect to inflammation, Chen et al. showed the anti-inflammatory properties of epFAs in the liver, demonstrating that 14,15-EET decreased PA-induced pro-inflammatory cytokine production (e.g. TNF $\alpha$, IL6, and IL1 $\beta$ ) in HepG2 cells [48]. This was accompanied by decreased NFאB signaling, consistent with previous studies connecting epFAs to NFkB blockade [8]. In addition to hepatocytes, cell culture studies also support a mechanistic role for epFAs in monocytes/macrophages. Chen et al. investigated 14,15-EET's ability to alter cytokine release and phagocytosis in RAW264.7 murine macrophages. 14,15-EET had no effect on 
phagocytic ability when administered alone but did decrease LPS-induced expression of pro-inflammatory cytokines TNF $\alpha$, IL1 $\beta$, and IL6 [38]. By contrast, LA-derived 9,10EpOME and 12,13-EpOME were shown to induce pro-inflammatory cytokine expression (Il6 and Mcp1) in RAW264.7 cells in a dose-responsive manner [80]. Interestingly, sEH hydrolysis deactivated these LA-derived epFAs; corresponding dihyroxyFAs 9,10DiHOME and 12,13-DiHOME did not influence $I l 6$ and Mcpl expression. These results suggest an immunomodulatory role for $\mathrm{sEH}$ in either preventing or permitting macrophage activation, depending on the epFA or dihydroxyFA considered.

Mechanistically, epFAs may act via several receptors, including peroxisome proliferator-activated receptors alpha and gamma (PPAR $\alpha$ and PPAR $\gamma$, respectively) $[10$, 81]. These PPARs are considered therapeutic targets for the treatment of liver diseases like NAFLD due to their role in regulating glucose and lipid metabolism [82]. Subsequently, inhibition of PPAR $\gamma$ abrogates the beneficial effects of sEH inhibition in various diseases [83-85], and inhibition of PPAR $\alpha$ abrogated the protective effect of TPPU on steatosis in mice in the study by Yao et al. [49]. At the level of individual epFAs, competition binding studies show that EETs (specifically 5,6-EET, 8,9-EET, 11,12-EET, and 14,15-EET) bind PPAR $\gamma$ with dissociation constants in the low micromolar range [81]. EPA-derived 17,18EpEET was similarly shown to act through PPAR $\gamma$ to exert its anti-inflammatory effects [10]. Further, 11,12-EET, 14,15-EET, and 14,15-DiHETE, the hydrolysis product of 14,15-EET, were shown to activate PPAR $\alpha$ in a luciferase reporter system, with 14,15 DiHETE activating PPAR $\alpha$ at a level nearly three times higher than that of 14,15-EET, suggesting that epFAs and dihydroxyFAs may interact with nuclear receptors differently $[49,86]$. Some sEHIs are may even act as PPAR $\alpha$ ligands themselves [87], suggesting that 
sEHI-mediated control of inflammation and lipid/glucose metabolism through PPAR receptors may be controlled both directly by the sEHI and indirectly by epFAs and dihydroxyFAs.

Another important point to consider is that there may be differences in the biological activities of epFAs based on the parent PUFAs. Data reviewed here suggests that omega-3-derived epFAs may have greater efficacy than omega-6-derived epFAs in blocking cellular characteristics of liver pathology. This idea is analogous to the more established concept that omega-3 PUFAs themselves are beneficial in liver disease, whereas omega-6 PUFAs are more pathogenic [88]. Specifically, Lopez-Vicario et al. showed that the omega-3 (EPA/DHA)-derived lipids included in their study (17,18-EpETE and 19,20-EpDPA) were more efficacious than the omega-6 (AA)-derived 14,15-EET in reducing PA-induced lipid accumulation/ER stress and promoting autophagy [42]. The differential effects of omega-3 vs. omega-6-PUFA-derived epFAs are often not directly considered; additional research in this area will likely address this question in the future.

\section{Knowledge Gaps}

While the initial discovery of epoxide hydrolases occurred about fifty years ago, the pathogenic role of sEH in liver diseases has been defined only recently. Clearly, sEH inhibition is an attractive therapeutic option in a spectrum of liver diseases, but future research in some key areas are needed to further elucidate its applications, limitations, and molecular mechanisms. One area that should be addressed is sex-specific responses to sEH inhibition in liver diseases. None of the studies reviewed here included female animals, despite the well-known sexual dimorphism of some liver diseases such as NAFLD in both humans and rodents [89]. Importantly, evidence suggests estrogens can down-regulate sEH 
expression, meaning females may have higher baseline epFA levels affording some protection against liver disease, although no studies have addressed this question directly [90-92]. Future research should also address the efficacy of sEH inhibition in additional liver diseases like viral hepatitis, cholestatic liver disease, and HCC. These diseases share some characteristics with the liver diseases reviewed here (e.g. chronic inflammation, oxidative stress, ER stress, etc.), characteristics which epFA preservation may attenuate [93-95]. Next, the pool of epFAs is quite a large one, however the role and underlying mechanisms of only few have been investigated so far. Future research should incorporate additional epoxides from multiple PUFAs to elucidate key mediators of liver diseases, and to better understand whether omega-3 PUFAs truly do give rise to more beneficial epoxides than omega-6 PUFAs. Another important area to consider is that sEH is a dual-function enzyme with two domains, a C-terminal hydrolase domain (which sEHIs target), and an N-terminal phosphatase domain. While the hydrolase domain is well-studied, the phosphatase domain is not, meaning its potential contribution to liver pathology is unknown. Future studies should consider that the phosphatase activity remains active even after addition of sEHIs but is inactivated by genetic sEH deletion: this may help elucidate any differences in phenotype between sEHI-treated and $E p h x 2^{-/-}$animals.

The ultimate goal of sEHI research in preclinical animal models is translation to human diseases. It is important to mention that humans have various polymorphisms in the EPHX2 gene associated with increases or decreases in sEH activity [96, 97]. Specifically, substitution of lysine 55 with arginine (Lys55Arg) is associated with higher hydrolase activity, whereas substitution of Arginine 287 with glutamine (Arg387Gln) is associated with decreased hydrolase activity. These functional variants are associated with altered risk 
of cardiovascular disease and insulin sensitivity [98-100], and may contribute to heterogeneity in response to sEHI therapy between individuals. Clinical trials are nonetheless underway involving sEHIs for the treatment of insulin resistance, glucose intolerance, hypertension, endothelial dysfunction, and pain. Given the early success of these compounds, future clinical trials should help bring sEHIs into the market for liverspecific diseases in the coming years.

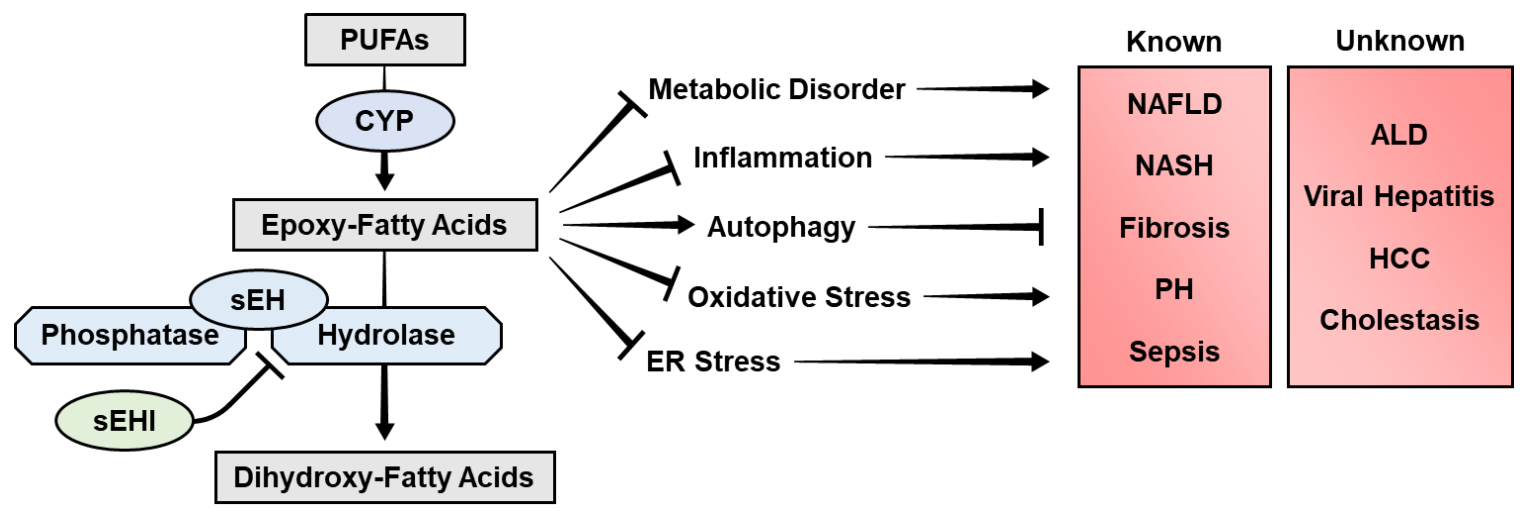

Figure 3. sEH inhibition in liver diseases: knowns and unknowns. sEH inhibitors preserve levels of endogenously produced epFAs by preventing their sEH hydrolysis. sEH inhibition improves disease phenotype in non-alcoholic liver disease, nonalcoholic steatohepatitis, hepatic fibrosis, cirrhotic portal hypertension, and cirrhotic sepsis. Individual epFAs are shown to improve insulin resistance, inflammation, autophagy, oxidative stress, and endoplasmic reticulum stress, suggesting a mechanistic link between $\mathrm{sEH}$ inhibitors and protection against liver diseases. No prior research has investigated sEH inhibition in ALD, viral hepatitis, hepatocellular carcinoma, or cholestatic liver disease. PUFAs, polyunsaturated fatty acids; CYP, cytochrome P450 2J/2C families; sEH, soluble epoxide hydrolase; sEHI, soluble epoxide hydrolase inhibitor; NAFLD, non-alcoholic fatty liver disease; NASH, non-alcoholic steatohepatitis; PTH, portal hypertension; ALD, alcohol-associated liver disease; HCC, hepatocellular carcinoma.

\section{sEH Inhibition and ALD}

Despite the growing research efforts to apply sEH inhibition to liver diseases, no studies to date have addressed the efficacy of sEH inhibition in ALD. Chronic, excessive consumption of ethanol $(\mathrm{EtOH})$ is the key etiological driver of ALD and produces significant changes in liver physiology. Like NAFLD, ALD begins with steatosis, a 
manifestation present in nearly all heavy drinkers [101]. However, in some drinkers, EtOHinduced steatosis may further progress to inflammation (alcohol-associated steatohepatitis), and end-stage ALD complications like cirrhosis, and HCC. Early-stage liver manifestations of ALD (i.e. steatosis and steatohepatitis) are reversible with cessation of EtOH consumption [102]; however, end-stage liver manifestations of ALD (i.e. cirrhosis and HCC) are irreversible and associated with significant mortality [101]. Importantly, ALD pathology shares several pathological mechanisms with NAFLD, such as inflammation and ER stress [101]. The innate immune system is activated following EtOHinduced bacterial translocation from the gut and EtOH-induced liver cell death, leading to release of damage-associated molecular patterns, activation/recruitment of immune cells in the liver, and further production of reactive oxygen species and inflammatory cytokines [101]. EtOH consumption also leads to activation of the UPR and prolonged, pathological ER stress that further promotes liver inflammation, cell death, and steatosis [103]. sEHIs and epFAs have been demonstrated to attenuate inflammation, ER stress, and cell death associated with other liver diseases including NAFLD, suggesting that sEH inhibition may be a valid strategy in the management of ALD as well [38, 41, 43, 44, 51].

The purpose of the present research is to fill this knowledge gap by investigating sEH alterations in human ALD and testing the efficacy of sEH inhibition in ALD using pre-clinical animal models of the disease. We hypothesize that $\mathrm{sEH}$ inhibition by pharmacological or genetic means will attenuate the liver injury and inflammation associated with EtOH administration in mouse models of ALD. Generating data in support of this hypothesis will not only contribute to development of novel therapeutic strategies for ALD treatment, but also help elucidate molecular mechanisms of ALD pathogenesis. 


\section{CHAPTER 2}

\section{MATERIALS AND METHODS}

\section{Experimental Animals}

Male mice (C57BL/6) were purchased from The Jackson Laboratory (Bar Harbor, ME) and housed in a specific pathogen-free animal facility accredited by the Association for Assessment and Accreditation of Laboratory Animal Care under a protocol approved by the University of Louisville Institutional Animal Care and Use Committee (Nos. 15423 and 18418 to Dr. Irina Kirpich). Ephx $x 2^{-/-}$mice were obtained from the UC Davis Mouse Biology Program. Ephx2 knockout was confirmed by genotyping and Western blot for sEH with antibodies obtained from Dr. Bruce D. Hammock. The room was maintained on a 12-hour light/dark cycle.

\section{Experimental Design}

Two mouse models were employed that mimic human drinking patterns and development of ALD, the first being an acute-on-chronic (10+1) model where mice are provided an all liquid diet for 10 days followed by a single EtOH "binge" on day 11, delivered by oral gavage $(5 \mathrm{~g} / \mathrm{kg})$ 9h prior to euthanasia ( $\mathrm{n}=7-9$ mice/group, Figure $4 \mathbf{A})$. The second model is a chronic EtOH administration model where mice are provided an all liquid diet for six weeks, but with no EtOH binge. The mice are acclimated to the liquid diet with the following concentrations of $\mathrm{EtOH}(\% \mathrm{v} / \mathrm{v}): 0 \% \times 2 \mathrm{~d} ; 2 \% \times 2 \mathrm{~d}, 4 \% \times 7 \mathrm{~d}, 5 \%$ $x 7 d$, and $6 \% \times 21 d$. The mice were euthanized at the end of the feeding period $(n=7-15$ mice/group, Figure 4B). The control and EtOH liquid Lieber DeCarli diets were purchased from Bio-Serv (Flemington, NJ) (EtOH diet, cat no. F1341SP and control, F1340SP). The $\mathrm{EtOH}$ and control diets are identical and isocaloric with the exception that maltodextrin is 
substituted for EtOH in the control diet. Some mice received the sEH inhibitor 4-[[trans-4[[[[4-Trifluoromethoxy) phenyl] amino] carbonyl]-amino] cyclohexyl] oxy]-benzoic acid (t-TUCB) in the liquid diet, whereas other mice received only the EtOH vehicle (which was an insignificant source of EtOH) as a control. For each model, 8-12-week-old C57BL/6 males were randomized into one of four groups: pair-fed (PF), PF + t-TUCB, EtOH, and EtOH + t-TUCB. t-TUCB was a generous gift of Dr. Bruce Hammock (UC Davis) and was dissolved in EtOH and then added to the liquid diet at a concentration of $7.5 \mu \mathrm{g} / \mathrm{ml}$. This level was chosen because it is estimated to deliver a dose of $3 \mathrm{mg} / \mathrm{kg} / \mathrm{day} / \mathrm{mouse}$ based on average food consumption determined from previous experiments.

A

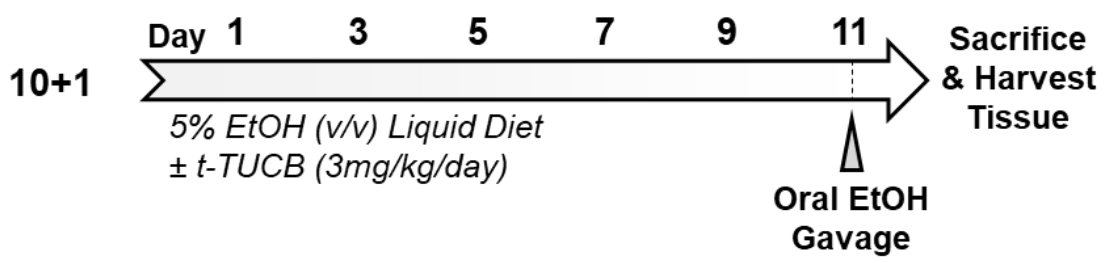

B

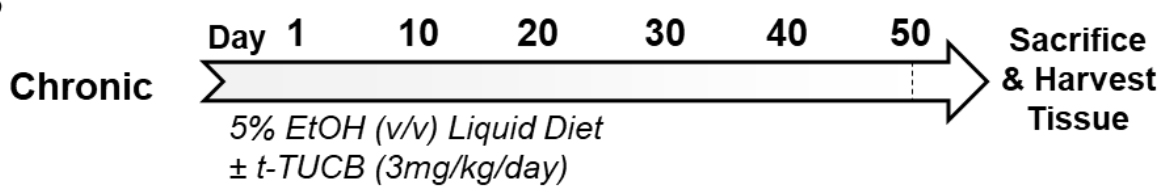

Figure 4. Feeding model schemes. A. Schematic representation of the chronic-binge " $10+1$ " Lieber DeCarli EtOH feeding model. B. Schematic representation of the chronic Lieber DeCarli EtOH feeding model.

\section{Assessment of Liver Damage}

At the termination of each experiment, mice were deeply anesthetized with ketamine/xylazine and blood collected from the inferior vena cava with heparinized syringes and transferred to microcentrifuge tubes. The plasma fraction was prepared by centrifugation at 2,000xg for $10 \mathrm{~min}$, aliquoted, and immediately stored at $-80^{\circ} \mathrm{C}$. Plasma 
alanine aminotransferase (ALT) activity was determined using the ALT/GPT reagent (Thermo Fisher, Waltham, MA). Portions of liver tissue from the left hepatic lobe were snap-frozen in liquid nitrogen and stored at $-80^{\circ} \mathrm{C}$ or were fixed in $10 \%$ neutral buffered formalin and embedded in paraffin for histological assessment. Formalin-fixed, paraffinembedded liver sections were stained with hematoxylin and eosin (H\&E) for overall morphology and steatosis, chloroacetate esterase (CAE) for neutrophil infiltration, terminal deoxynucleotidyl transferase dUTP nick end labeling (TUNEL) for apoptosis, and F4/80 for macrophage infiltration.

\section{qPCR}

Mouse total liver RNA was isolated with Trizol reagent (Thermo Fisher) and cDNAs were synthesized with qScript cDNA Supermix (Quanta Biosciences, Beverly, MA) followed by digestion with DNase (Thermo Fisher). qPCR reactions were performed on the cDNA equivalent of 10 ng of input RNA using PerfeCTa SYBR Green Fast Mix (Quanta Biosciences) on an Applied Biosystems 7900HT instrument (Foster City, CA). Data was analyzed by the $\Delta \Delta \mathrm{C}_{\mathrm{T}}$ method using $18 \mathrm{~S}$ as the calibrator [104]. Primer sequences are listed in Table 3. Analysis of Xbpl splice variant ratio was performed by standard PCR followed by gel electrophoresis, as previously described [105].

Table 3. qPCR primer sequences. $m$ designates mouse, $h$ designates human.

\begin{tabular}{|c|l|l|}
\hline Target & \multicolumn{1}{|c|}{ Forward Primer (5' to 3') } & \multicolumn{1}{|c|}{ Reverse Primer (3' to 5') } \\
\hline$m$ ' $p$ t $1 a$ & GCTGCACTCCTGGAAGAAGA & GGAGGGGTCCACTTTGGTAT \\
\hline$m$ Tnf- $\alpha$ & GTGATCGGTCCCCAAAGG & GGTGGTTTGCTACGACGTG \\
\hline$m$ Fasn & CAGTGGGTGGACTCTCTGAAG & GACAGCAGGATACACCGAATC \\
\hline
\end{tabular}




\begin{tabular}{|c|l|l|}
\hline$m I l-6$ & TGGAAATGAGAAAAGAGTTGTGC & CCAGTTTGGTAGCATCCATCA \\
\hline$m X b p l$ & ACTTGCACCAACACTTGCCATTTC & CAAGGTTCACTGCCTGTAATG \\
\hline$m X b p l-S p^{*}$ & GAGAACCAGGAGTTAAGAACACG & GAAGATGTTCTGGGGAGGTGAC \\
\hline$m C x c l 1$ & GGAAGTGTGATGACTCAGGTTTGC & GATGGTTCCTTCCGGTGGTTTCTTC \\
\hline$h C y p 2 j 2$ & CACAGGGACCCCACAGAGTG & AGGCATGCCCGCTTTCCTAT \\
\hline$h C y p 2 c 19$ & TCGATGGACATCAACAACCCT & ACTGTTGGTTTTGCTTTTCCTTCTC \\
\hline
\end{tabular}

*Primers used for determining Xbpl splicing.

\section{Western Blotting}

Mouse whole protein liver lysates were prepared by homogenization in radioimmunoprecipitation buffer supplemented with Halt ${ }^{\mathrm{TM}}$ protease and phosphatase inhibitors (Thermo Fisher) followed by centrifugation at 10,000g for 10 minutes to remove insoluble material. Protein concentrations were determined by Bradford assay [106] using reagent from Bio-Rad (Hercules, CA) with bovine serum albumin as a standard. $60 \mu \mathrm{g}$ of protein was diluted in $4 \mathrm{X}$ sample buffer (BioRad) and loaded onto a BioRad Criterion ${ }^{\mathrm{TM}}$ pre-cast acrylamide gel (Biorad cat. no. 5671127) and separated at 100 volts for 90 minutes. Proteins were electro-blotted onto a polyvinylidene difluoride membrane at 70 volts for two hours, blocked with $3 \%$ milk in TBST for 30 minutes, and incubated overnight with commercially available anti-C/EBP homologous protein (CHOP), inositol-requiring enzyme-1 $\alpha$ (IRE1 $\alpha$ ), or phosphorylated IRE1 $\alpha$ (Phospho-IRE1 $\alpha$ ) antibodies (Thermo Fisher). The membranes were washed and incubated in horseradish peroxidase-conjugated secondary antibodies and imaged using a BioRad Chemidoc ${ }^{\mathrm{TM}}$ imaging system.

\section{Plasma t-TUCB Analysis}


Mouse plasma levels of t-TUCB were measured by mass spectrometry in the laboratory of Dr. Bruce D. Hammock at the University of California, Davis.

\section{Liver triglycerides}

Mouse hepatic lipids were extracted with chloroform and methanol as previously described [107] and triglycerides (TGs) were measured using reagents from Thermo Fisher Scientific Inc. (Waltham, MA) according to the manufacturers' instructions.

\section{Targeted Lipidomic Analysis of epFAs in Human and Mouse Liver Tissue}

Explanted human liver tissue was procured from the Johns Hopkins University Transplant Center and analyzed by the Wayne State University Lipidomic Core Facility as previously described [108]. A similar analysis was conducted on mouse livers isolated from mice in our chronic EtOH feeding model.

\section{Cell Culture}

HepG2 human hepatoma cells were cultured and treated with $1 \mu \mathrm{M}$ 19,20-EpDPA (Cayman Chemical, Ann Arbor, MI) for 24 hours in a 96-well plate format plated at 10,000 cells per well. Cells were then stained with Annexin V Alexa Fluor 647 conjugate (Life Technologies, Carlsbad, CA) and Fluo-4 AM (Thermo Fisher Scientific, Waltham, MA) for 15 minutes. Mean ring/circle average fluorescent intensity was analyzed for each well by cellomics analysis with the Thermo Fisher ArrayScan VTI HCS instrument (Thermo Fisher Scientific, Waltham, MA). Experiments were performed in eight replicate wells.

RAW264.7 macrophages were cultured and treated with for $21 \mathrm{~h}$ with $1 \mu \mathrm{M} 17,18$ EpETE or 19,20-EpDPA (Cayman Chemical, Ann Arbor, MI) solubilized in DMSO (final 
DMSO concentration was $0.034 \%$ ) in a 24 -well plate format plated at 175,000 cells per well. Cells were then challenged with $10 \mathrm{ng} / \mathrm{mL}$ LPS for $3 \mathrm{~h}$ and then total RNA was isolated as per the manufacturer's instructions (Qiagen, Germantown, MD) and cDNA was synthesized for qPCR analysis of pro-inflammatory cytokine mRNA analysis as described above. Experiments were performed in three replicate wells.

\section{Statistical Analysis}

Data are shown as mean \pm standard error of the mean (SEM). GraphPad Prism 8 software (GraphPad Software, San Diego, CA) was used to perform one sample Student's t-tests(for two group comparison) or one-way ANOVA tests (for more than two groups) for data following a normal distribution and Mann-Whitney and Kruskal Wallis H tests for data following a non-normal distribution. Data are considered significant at $\mathrm{p}<0.05$. 


\section{CHAPTER 3}

\section{RESULTS}

\section{Lipidomic Analysis of Human Liver Tissue}

To determine whether there are alterations in sEH activity and an imbalance in the pool of epFAs/dihydroxyFAs in human ALD, we obtained explanted human liver tissue from both patients with severe alcoholic hepatitis $(\mathrm{sAH}, \mathrm{n}=7)$, a severe clinical manifestation of ALD, and control non-ALD/AH patients $(n=5)$ from Drs. Z. Sun and A. Ahmadi through the John Hopkins University Clinical Resources Center for Alcoholic Hepatitis Investigations (under grant 1R24AA025017-01). We then performed targeted lipidomic analysis with these liver samples. The average model end-stage liver disease (MELD) score for the ALD patients was 37. Figure 5A shows representative liver histopathology by H\&E staining, which is characterized by steatosis and immune cell infiltration. Targeted lipidomics analysis showed that several epFAs derived from AA $(5,6-$ EET and 11,12-EET) and DHA (16,17-EpDPA and 19,20-EpDPA) were significantly decreased in ALD patients' liver tissue relative to healthy control tissue (Figure 5C). We then tested whether the decrease in these EpFAs was accompanied by an increase in EPHX2 (the gene encoding human sEH) expression. To this end, we assayed the mRNA expression of EPHX2 by qPCR in our liver samples and discovered that ALD patients' liver tissue had a significant increase in the expression of EPHX2 compared to controls (Figure 5B). Additionally, these patients' liver tissue also had lower expression of several CYPs involved in epoxygenation of fatty acids, including CYP2J2, CYP2C19, and CYP4A11, as measured by qPCR (Figure 5D). The combination of increased $\mathrm{sEH}$ and decreased CYP expression is consistent with a decrease in epFA levels, given that CYPs 
are responsible for their production and $\mathrm{sEH}$ is responsible for their degradation. We previously demonstrated that this pattern was recapitulated in a mouse model of ALD [108], thus providing a system whereby we can investigate the efficacy of sEH inhibition in experimental ALD.

A
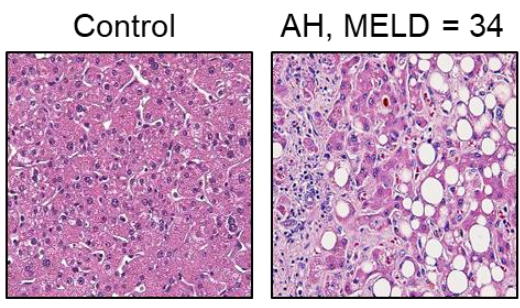
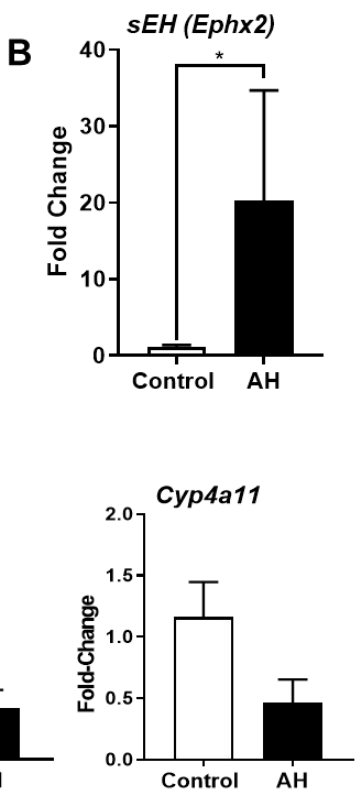

C
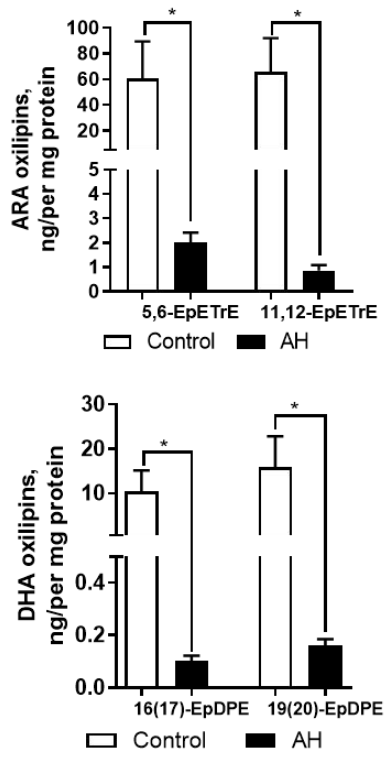

Figure 5. Liver tissue from Human ALD patients has decreased levels of epFAs. A. Representative H\&E-stained liver sections from a patient with alcoholic hepatitis (MELD score 34, right) and a control patient (left), 200X magnification. B. qPCR analysis of mRNA expression of EPHX2 in control and ALD human liver tissue. $\mathbf{C}$. Targeted lipidomics analysis of liver tissue epFAs in control and ALD human liver samples. The top and bottom graphs are levels of AA-derived and DHA-derived epFAs, respectively. D. qPCR analysis of mRNA expression of epFA-producing CYP450s in control and ALD human liver tissue. All data are represented as mean \pm standard error of the mean, with significance considered as $\mathrm{p}<0.05$.

\section{sEH Inhibition Improved Liver Injury in Two Mouse ALD Models}

To assess the efficacy of sEH inhibition in experimental ALD, we administered the sEH inhibitor t-TUCB orally in the liquid diet in two mouse models of ALD that recapitulate human drinking behavior: a chronic EtOH administration model and an acute- 
on-chronic (10+1) model. The chronic model mimics long-term EtOH consumption and produces a modest increase in liver injury and inflammation driven by macrophages [109]. The 10+1 model mimics a common pattern of drinking behavior among patients with ALD, which is to consume a steady amount of EtOH chronically with a sudden escalation (chronic-binge behavior). This model is characterized by significant liver injury, steatosis and inflammation driven by neutrophil infiltration [110]. Figure 6A outlines these two ALD models. There was no effect of t-TUCB on body weights or food consumption in either of the experiments (data not shown).

To determine whether t-TUCB increased the levels of liver epFAs, we performed targeted LC-MS lipidomics analysis (Wayne State Lipidomics Core Facility) and assessed the ratio of 19,20-EpDPA to its cognate dihdroxyFA 19,20-DiHDPA and the ratio of 17,18EpETE to its cognate diol, 17,18-DiHETrE as an indirect measure of sEH activity (Figure 6B). As expected, there was an increase in the epFA:dihydroxyFA ratio for each pair in mice administered t-TUCB compared to vehicle controls, indicating decreased $\mathrm{sEH}$ activity in the former. Importantly, sEH inhibition by t-TUCB significantly decreased EtOH-induced liver injury in the $10+1$ model to a lesser degree in the chronic model as determined by plasma ALT activity (Figure 6C). To determine if variations in t-TUCB consumption between experiments was responsible for this effect, we analyzed plasma levels of t-TUCB and correlated them to plasma ALT activity (Figure 6D). We saw no positive correlation between plasma t-TUCB levels and plasma ALT activity, indicating that all mice received a therapeutic dose. 
A

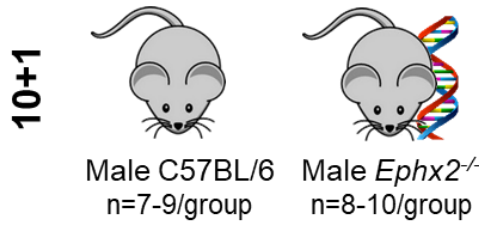

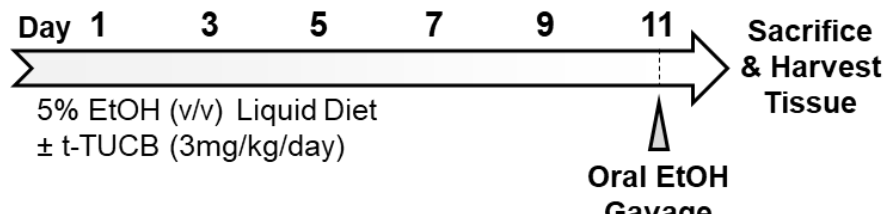

Gavage

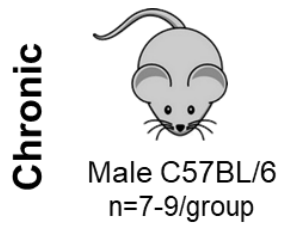

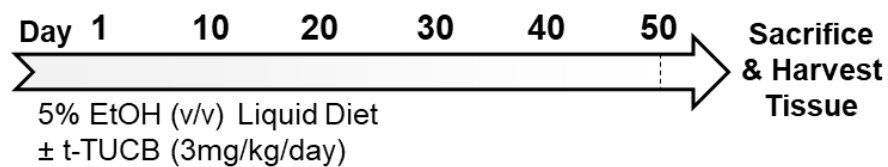

B
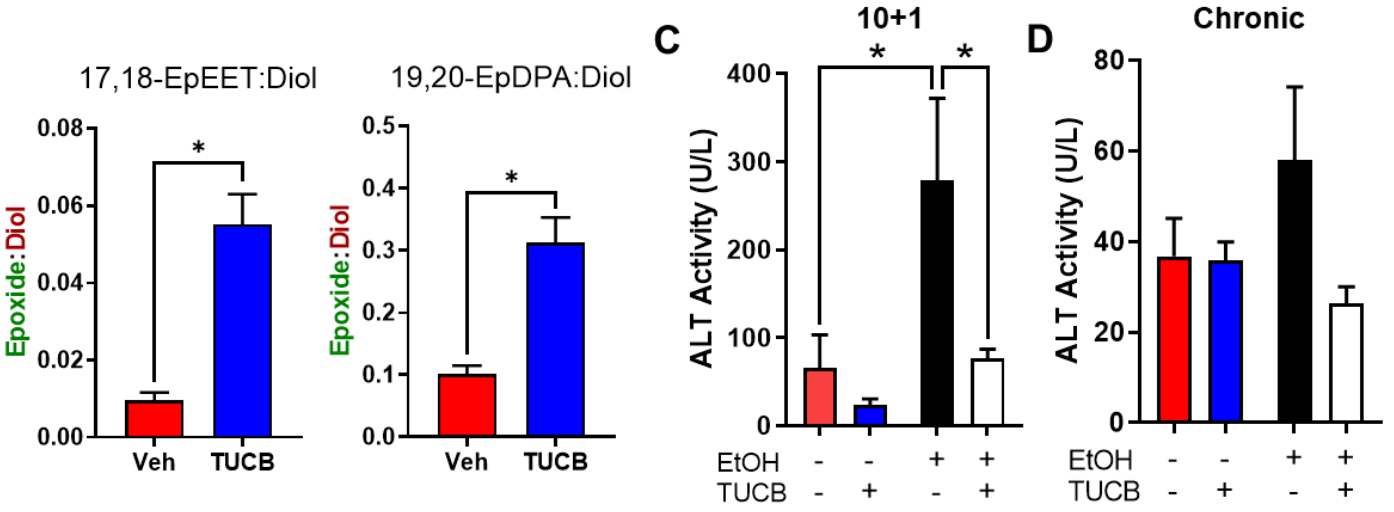

Figure 6. sEH Inhibition Decreased Liver Injury in Multiple Mouse Models of ALD. A. Schematic representation of experimental mouse models of ALD. Upper scheme represents the 10+1 model of EtOH administration, lower scheme represents the chronic EtOH model. B. Targeted lipidomic analysis of mouse liver tissue from the chronic experiment. Red bars represent mice from the EtOH group and blue bars represent mice from the EtOH $+\mathrm{t}$-TUCB group. Data are shown as the ratio of epFA to dihydroxyFA for 17,18-EpETE/17,18-DiHETrE and 19,20-EpDPA/19,20-DiHDPA on the left and right, respectively. C. Plasma ALT activity from the $10+1$ model of EtOH administration. D. Plasma ALT activity from the chronic model of EtOH administration. All data are represented as mean \pm standard error of the mean, with significance considered as $p<0.05$. 


\section{t-TUCB did not Affect Hepatic Steatosis}

Hepatic steatosis is a hallmark of ALD. To determine if protection against steatosis is a mechanism by which t-TUCB decreased liver injury, we analyzed lipid accumulation by H\&E histopathology and liver TG analysis. In the chronic model, we observed a marked EtOH-induced increase in hepatic fat content on H\&E-stained liver sections (Figure 7A), accompanied by a significant increase in hepatic TGs (Figure 7B). In this model, t-TUCB had only a small, non-statistically significant ability to reduce hepatic steatosis, and,
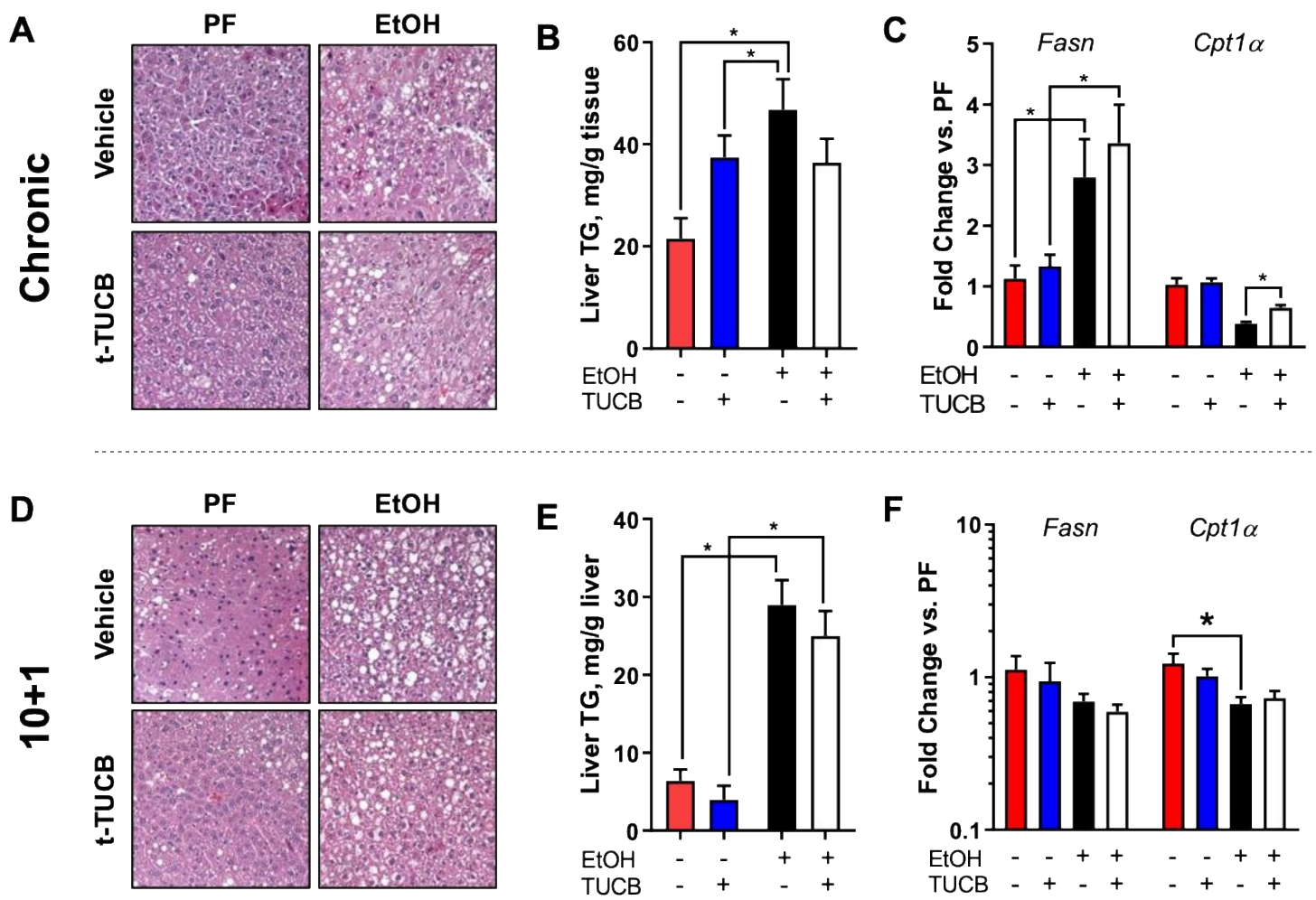

Figure 7. sEH Inhibition does not Affect Hepatic Steatosis. A and D. Representative images of H\&E-stained liver sections from mouse livers from the chronic EtOH administration model and 10+1 EtOH administration model, respectively, 200X magnification. B and E. Analysis of liver triglyceride levels, normalized to liver weight, in the chronic EtOH administration model and 10+1 EtOH administration model, respectively. C and F. qPCR analysis of liver mRNA expression of Fasn and Cptla from mouse livers in the chronic EtOH administration model and 10+1 administration model, respectively. All data are represented as mean \pm standard error of the mean, with significance considered as $\mathrm{p}<0.05$. 
interestingly, t-TUCB significantly increased hepatic TGs in the PF + TUCB group. In addition to analyzing hepatic TG levels, we also assayed the expression of several key genes regulating fatty acid homeostasis (Figure 7C). Analysis by qPCR revealed that the expression of fatty acid synthase (Fasn) was increased in the EtOH-fed groups in the chronic model but was not reduced effect by t-TUCB. By contrast, the EtOH-mediated decrease in carnitine palmitoyltransferase 1 alpha $(C p t 1 \alpha)$, a gene related to fatty acid beta oxidation, was significantly rescued by t-TUCB. In the 10+1 model, we observed a similar EtOH induction of hepatic steatosis by evaluation of $\mathrm{H} \& \mathrm{E}$-stained liver sections and liver TG analysis (Figure 7D and Figure 7E). t-TUCB similarly caused a slight reduction in hepatic steatosis but was not statistically significant. qPCR analysis of Fasn and Cpt1 $\alpha$ expression showed no significant difference between mice administered t-TUCB vs. vehicle controls (Figure 7F).

\section{SEH Inhibition Attenuated Chronic EtOH-Associated Liver Inflammation}

To determine whether protection against inflammation is a mechanism by which $\mathrm{t}$ TUCB decreased liver injury, we performed CAE staining and qPCR analysis of proinflammatory cytokine production. In the chronic model, we observed a decrease in the number of liver neutrophils, as determined by CAE staining, in the livers of mice treated with t-TUCB in both PF and EtOH-fed mice (Figure 8A and Figure 8B). Additionally, EtOH-induced expression of the pro-inflammatory cytokine Cxcll was significantly reduced by t-TUCB in EtOH-fed mice. EtOH administration also induced expression of the pro-inflammatory cytokine $I l 6$, which was rescued by t-TUCB, although these changes were not statistically significant. 
A
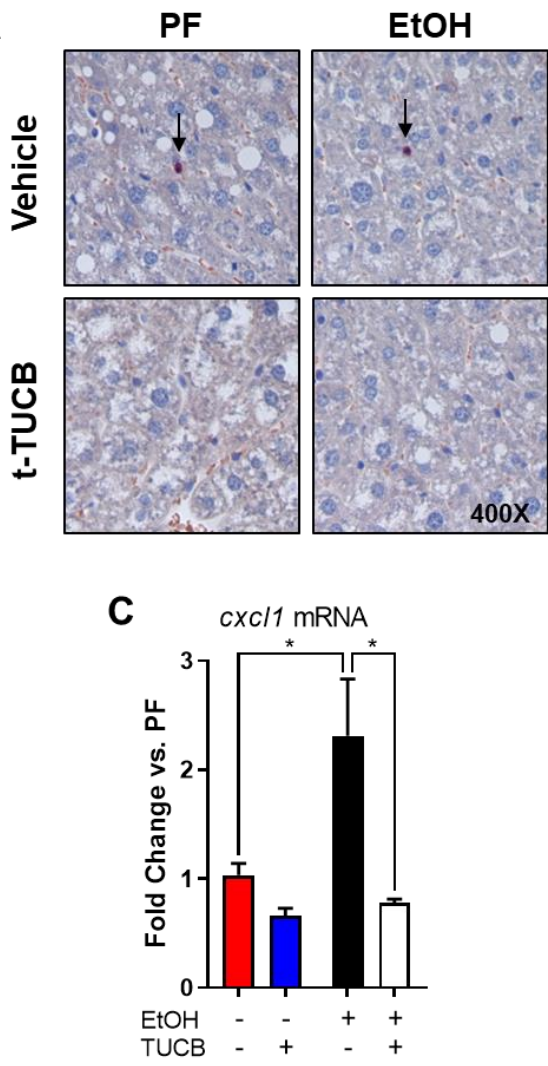

B

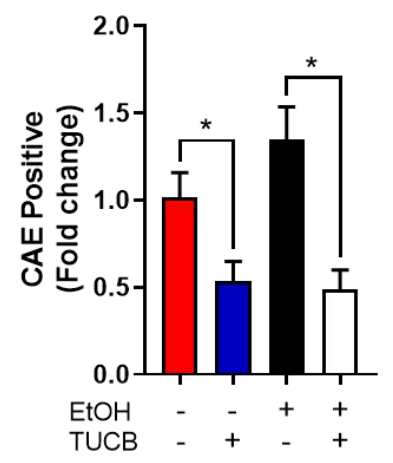

Figure 8. sEH Inhibition Improves Chronic EtOH Consumption-Associated Liver Inflammation. A. Representative images from CAE-stained liver sections from the chronic EtOH administration model. Arrows indicate CAE-positive cells (neutrophils), 400X magnification. B. Quantification of CAE staining. Ten digital fields were analyzed for CAE-positive cells per mouse liver section. C and D. qPCR analysis of CXcll and Il-6 expression in mouse livers from the chronic EtOH administration model, respectively. All data are represented as mean \pm standard error of the mean, with significance considered as $\mathrm{p}<0.05$.

\section{sEH Inhibition Attenuated Chronic EtOH-Associated Liver ER Stress}

ER stress can contribute to ALD pathogenesis, and is implicated in liver inflammation, apoptosis, and steatosis [111]. Therefore, we assayed activation of the UPR by determining the expression of key genes involved in this process. In the chronic model, we found strong induction of CHOP protein expression in the livers of EtOH-fed mice as determined by Western blot (Figure 9A and Figure 9B). In EtOH + t-TUCB treated mice, 
A
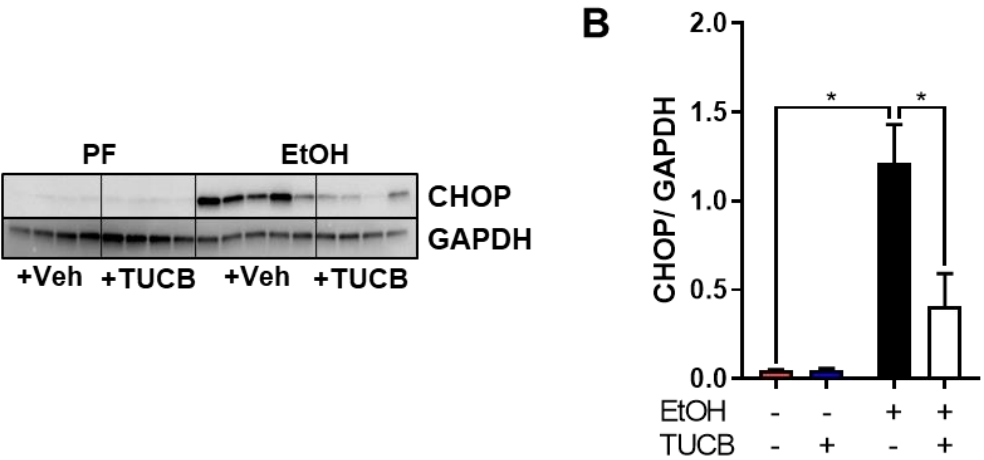

C
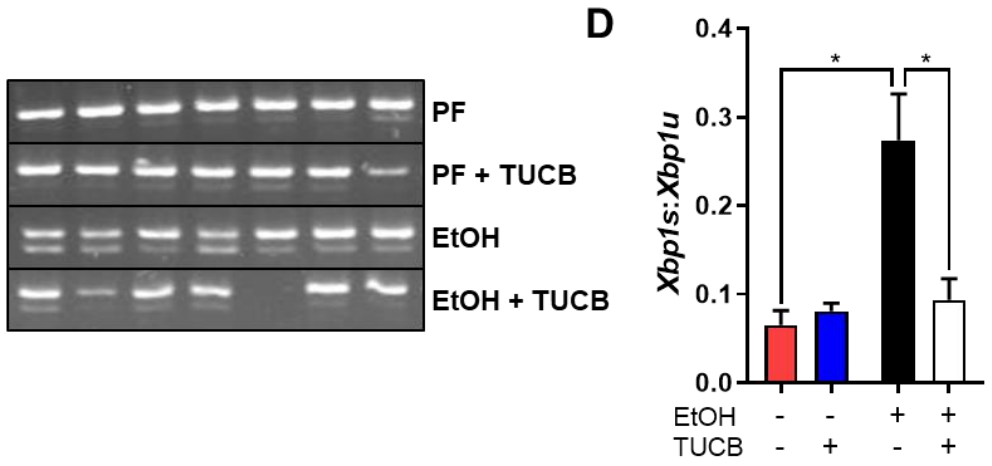

Figure 9. sEH Inhibition Improves Chronic EtOH-Associated Liver ER Stress. A. Western blot analysis of CHOP protein in livers of mice in the chronic EtOH administration model. GAPDH served as the loading control. B. Densitometry analysis of CHOP expression. Data are normalized to GAPDH expression. C. Standard qPCR and gel electrophoresis analysis of Xbpl splicing. Upper bands are unspliced Xbpl $(X b p 1 u)$, bottom bands are spliced Xbpl $(X b p 1 s)$. D. Densitometry analysis of the $X b p 1 s: X b p 1 u$ ratio. All data are represented as mean \pm standard error of the mean, with significance considered as $\mathrm{p}<0.05$.

however, there was a significant reduction in CHOP protein. We also determined the expression of phospho-IRE1 $\alpha$, which induces CHOP expression, and found no significant differences between vehicle and t-TUCB treated mice (data not shown). Further, we assayed for differences in splicing of Xbpl mRNA from its unspliced to its spliced form (unspliced, $X b p l u$, spliced, $X b p l s$ ). It is difficult to determine differences in mRNA expression of the two variants of Xbpl by qPCR because they differ by only 26 nucleotides. Therefore, we used standard PCR with followed by high-resolving gel electrophoresis and densitometry to determine differences in abundance between Xbplu and Xbpls (Figure 
9C). In the chronic model, EtOH increased the Xbpls:Xbplu ratio which was reduced to PF levels in the EtOH + t-TUCB group (Figure 9D).

\section{Genetic Ablation of sEH Similarly Decreased Liver Injury and Inflammation}

In order to validate our results with pharmacological inhibition of sEH by t-TUCB administration on ALD, we used whole-body sEH knockout $\left(E p h x 2^{-/-}\right)$mice in the $10+1$ model of EtOH administration. As with mice administered t-TUCB, we observed a reduction in liver injury by plasma ALT activity in EtOH-fed Ephx $x 2^{-/-}$mice compared to EtOH-fed WT controls (Figure 10A). We next aimed to determine whether the liver phenotype observed in t-TUCB treated mice with respect to steatosis and inflammation was recapitulated in Ephx $2^{-/-}$mice. To this end, we stained liver sections with H\&E to evaluate steatosis and used ELISA to measure the levels of hepatic pro-inflammatory cytokines CXCL1 and IL6. As with t-TUCB treated mice, Ephx $2^{-/-}$mice fed EtOH had no significant difference in hepatic steatosis by H\&E staining (Figure 10B and Figure 10C). We observed a similar trend in liver inflammation: Eph $x 2^{-{ }^{--}}$mice fed EtOH had a significant decrease in liver CXCL1 protein and a decrease in liver IL6 protein, although the reduction in Il6 was not statistically significant (Figure 10D and Figure 10E). 

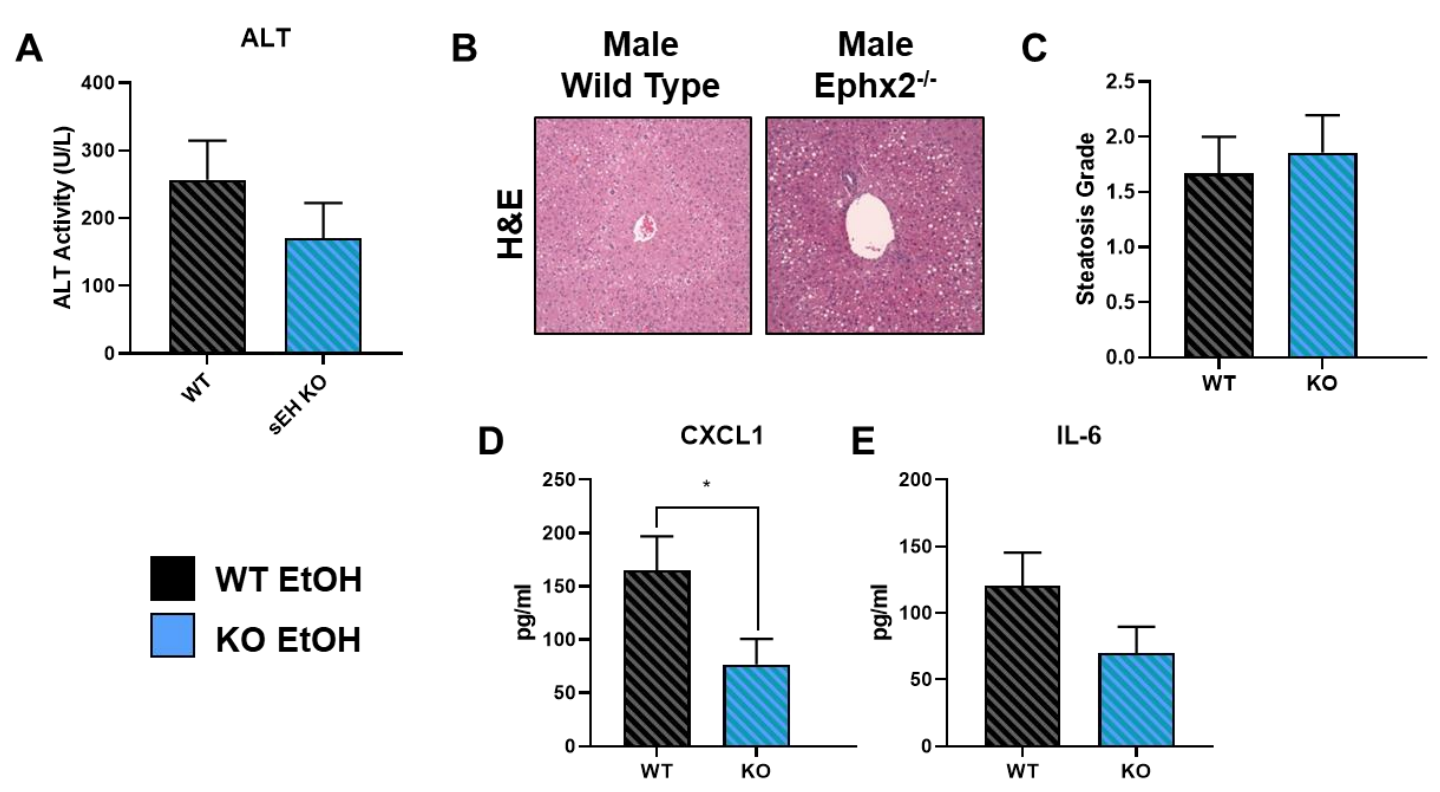

Figure 10. Genetic Ablation of sEH Similarly Attenuates Liver Injury and Inflammation. A. Plasma ALT activity. B. Representative images of H\&E-stained liver sections from WT and $E p h x 2^{-/-}$mice, 100X magnification. C. Quantitation of liver steatosis by analysis and grading of H\&E-stained liver sections. D and E. ELISA analysis of Cxcl1 and Il-6 protein levels in mouse livers from WT and Ephx $2^{-/-}$mice, normalized to $\mathrm{mL}$ liver homogenate. All data are represented as mean \pm standard error of the mean, with significance considered as $\mathrm{p}<0.05$.

\section{EpFAs Prevented Hepatocyte Apoptosis and Macrophage-Mediated Cytokine}

\section{Production}

To determine whether individual epFAs contribute to improvements in cellular pathologies associated with ALD, we conducted an in vitro analysis. We first treated serum-starved HepG2 cells with 19,20-EpDPA for 24 hours. To analyze apoptosis and ER stress, we then stained the cells with Annexin V-FITC and Fluo4-AM, respectively, and measured fluorescence by cellomics (Figure 11A). 19,20-EpDPA significantly decreased the Annexin V signal compared to control, indicating a decrease in HepG2 apoptosis (Figure 11C and Figure 11D). Similarly, 19,20-EpDPA-treated HepG2 cells had a 
significant decrease in Fluo-4 AM fluorescence (a measure of intracellular free calcium), indicating decreased ER stress by intracellular free calcium (Figure 11B and Figure 11D).

Next, we aimed to determine whether epFAs could prevent LPS-induced proinflammatory cytokine expression macrophages. To this end, we pre-treated RAW264.7 macrophages with 17,18-EpETE or 19,20-EpDPA for 21 hours prior to a 3-hour LPS challenge, then assayed cytokine expression by qPCR (Figure 12A). LPS administration caused a nearly 300-fold increase in Cxcll mRNA and a nearly 30-fold increase in Tnfa mRNA in RAW264.7 cells compared to a DMSO control. Remarkably, cells treated with

A

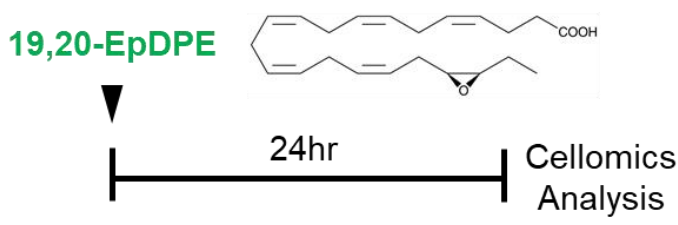

HepG2 Cells

C

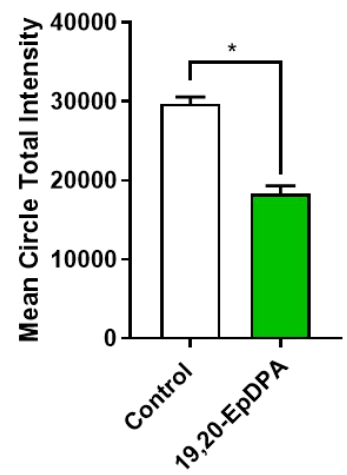

D

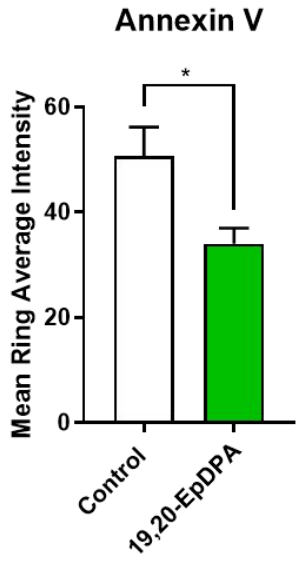

B
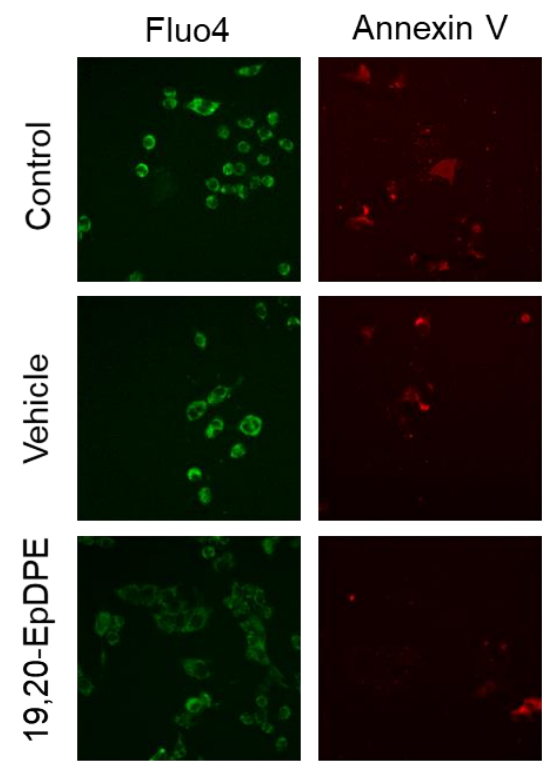

Figure 11. 19,20-EpDPA Prevents Hepatocyte Cell Death. A. Schematic representation of cell culture experiments. Serum-starved HepG2 cells were exposed to 19,20-EpDPA for 24 hours prior to Fluo4 and Annexin V staining and cellomics analysis. Cells were plated in 10 replicate wells. B. Representative fluorescent images of Fluo4 and Annexin V-stained HepG2 cells, 400X magnification. C and D. Quantification of Fluo4 and Annexin V fluorescent intensity by cellomics, respectively. All data are represented as mean \pm standard error of the mean, with significance considered as $\mathrm{p}<0.05$. 
LPS + 17,18-EpETE or LPS + 19,20-EpDPA had reduced Cxcl1 mRNA expression by roughly a third compared to LPS alone (Figure 12B). Similarly, these two epFAs also significantly decreased LPS-induced Tnf $\alpha$ mRNA expression by almost a half compared to LPS alone (Figure 12C).

A

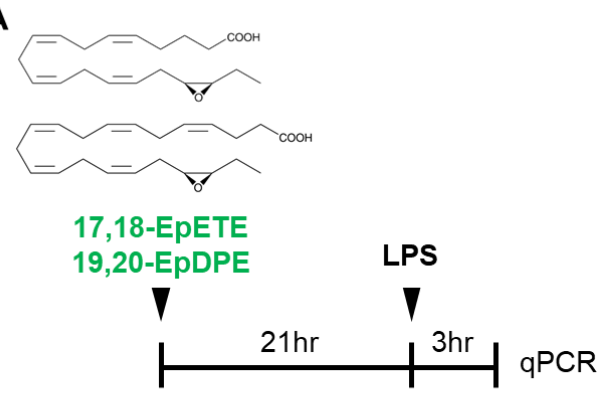

RAW264.7 Cells
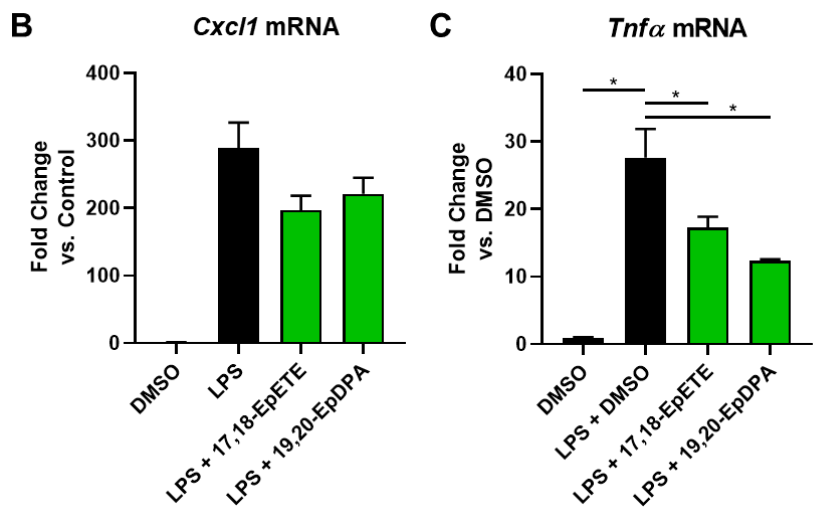

Figure 12. EpFAs Prevent Macrophage-Mediated Pro-Inflammatory Cytokine Release. A. Schematic representation of cell culture experiment. RAW264.7 cells were exposed to 17,18-EpETE or 19,20-EpDPA 21 hours prior to a 3-hour LPS challenge, then harvested for qPCR analysis of pro-inflammatory cytokine expression. Cells were plated in triplicate wells. B and C. qPCR analysis of mRNA expression of Cxcll and Tnfo in RAW264.7 cells. All data are represented as mean \pm standard error of the mean, with significance considered as $\mathrm{p}<0.05$. 


\section{CHAPTER 4}

\section{DISCUSSION}

EpFAs have emerged as mediators of inflammation, steatosis, autophagy, ER stress, and more [8, 12, 13, 42], and are rapidly deactivated by sEH hydrolysis [1, 15]. sEH inhibition has been demonstrated to be a viable treatment strategy for several diseases, including those of the liver, although prior to the current study, no studies had applied sEH inhibition to the prevention of ALD. Importantly, in human ALD samples, we found a decrease in the epFA pool which was accompanied by increased EPHX2 expression. Therefore, we hypothesized that sEH inhibition may act to preserve the remaining epFA pool, thereby attenuating liver injury and inflammation. In our models, both pharmacological sEH inhibition by t-TUCB and whole-body genetic ablation of sEH prevented ALD outcomes, including liver injury, inflammation, and ER stress, while having no significant effect on hepatic steatosis. These findings suggest $\mathrm{sEH}$ may be a novel drug target in ALD, an important finding, given that there are currently no FDAapproved therapies for ALD. Our findings also corroborate previous reports that sEH inhibition is effective in treating liver inflammation and ER stress, which are common pathogenic mechanisms in multiple liver diseases [62, 112].

In order to determine a patient population that may benefit most from sEH inhibition, we used two pre-clinical mouse models of ALD that recapitulate different severities of human ALD. The chronic model mimics many early features of ALD such as hepatic steatosis, macrophage-driven inflammation, and injury [113], whereas the chronicbinge 10+1 model recapitulates manifestations of end-stage ALD such as acute liver injury and neutrophil infiltration $[110,114]$. Interestingly, we discovered that between the two 
models, sEH inhibition afforded better protection against liver injury in the chronic-binge model. Liver injury in the chronic binge model is primarily driven by neutrophil infiltration [114], meaning that the beneficial effects of sEH inhibition in ALD may be primarily antiinflammatory, which is consistent with evidence of the anti-inflammatory effects of epFAs $[38,43,44,48]$.

We found no significant effects of sEH inhibition on EtOH-induced hepatic steatosis. However, in the chronic model, we did observe a slight protection against fat accumulation by t-TUCB that was accompanied by a similar minor rescue of the EtOHinduced decrease in Cptl $\alpha$ expression. Cptl $\alpha$ encodes a carnitine palmitoyltransferase critical in regulating beta oxidation, the major pathway of fatty acid ester degradation in the fatty liver [115]. By contrast, we saw no protection against EtOH-induced expression of lipogenic fatty acid synthase (Fasn). A static level of Fasn expression coupled with increased $C \operatorname{tpl} \alpha$ may indicate a preference for fatty acid breakdown rather than synthesis in t-TUCB-treated mice, although our histopathology provides only weak evidence for this in both pharmacological and genetic ablation of sEH. These data indicate that protection against fatty liver degeneration is likely not a major mechanism of sEH-mediated reduction in liver injury in our models, despite improvements demonstrated by others in steatosis by sEHIs or CYP2J2 overexpression in non-alcoholic liver diseases [40, 42, 43, 47-49].

sEH inhibition decreased neutrophil-driven infiltration in both PF and EtOH-fed mice in our chronic model. Neutrophils are critical mediators of the EtOH-mediated innate immune response that suppress bacterial infection and clear damaged cells, but also contribute to liver injury and fibrosis through the production of reactive oxygen species, proteases, pro-inflammatory cytokines such as $I l-6$, and neutrophil-attracting chemokines 
such as Cxcl1 [112]. The expression of these cytokines was decreased by both t-TUCB and genetic ablation of sEH in our whole-body knockout mice. Taken together, these data suggest that reduction of inflammation is a major mechanism by which t-TUCB affords protection against liver injury, in line with numerous studies showing decreased liver inflammation in other liver diseases mediated by sEHIs [38, 40, 43, 44].

As with NAFLD, ER stress is a contributor to ALD pathogenesis that is marked by activation of the UPR, which can ultimately lead to steatosis, hepatocyte apoptosis, and subsequently, inflammation $[111,116,117]$. sEH inhibition by t-TUCB decreased splicing of $X b p l u$ to $X b p l s$, which is an active transcription factor that can induce expression of pro-apoptotic transcription factor CHOP [118], thereby linking ER stress to hepatocyte cell death and liver inflammation. Indeed, our t-TUCB-mediated protection against ER stress was accompanied by a decrease in inflammation. This finding is consistent with previous reports indicated attenuated ER stress by sEHI administration in NAFLD and liver fibrosis $[41,42,51]$. ER stress is also highly connected to steatosis; ER stress is not only a product of steatosis but a driver of it as well [117]. Interestingly, we found that while sEH inhibition abrogated markers of ER stress, there was no considerable protection against steatosis, indicating that while steatosis and ER stress may contribute to each other in a sort of 'vicious cycle', sEH inhibition largely affected ER stress alone.

While the pool of epFAs is large and these lipid mediators are produced from numerous PUFAs, our in vitro studies identified several key epFAs that may drive our in vivo protection against liver injury, namely, EPA-derived 17,18-EpETE and DHA-derived 19,20-EpDPA. Numerous previous reports highlight the ability of these epFAs to improve liver disease outcomes in cell culture [42]. Our data suggest the ability of these epFAs to 
protect against liver injury by acting on multiple cell types, specifically, hepatocytes and macrophages. 19,20-EpDPA reduced hepatocyte cell death, a pathological feature of ALD that contributes to liver injury [119]. This was accompanied by reduced hepatocyte ER stress, corroborating previous evidence that individual epFAs (14,15-EET, 17,18-EpETE, and 19,20-EpDPA) decreased activation of the UPR in primary mouse hepatocytes [42]. Further, 17,18-EpETE and 19,20-EpDPA prevented the LPS-induced release of proinflammatory chemokines/cytokines $\mathrm{Cxcll}$ and $\operatorname{Tnf} \alpha$ from immortalized macrophages. In this experiment we used LPS to stimulate cytokine release because LPS is a major bacterial endotoxin produced by gut flora that translocates to the liver following EtOH-induced leaky gut [120]. Liver macrophages like KCs respond to bacterial signals such as LPS to mediate innate immunity in the liver and are the main sources of pro-inflammatory cytokine production $[121,122]$. Previous studies show that epFAs can modulate PAinduced or baseline macrophage cytokine release $[48,80]$, but our study is the first to show that epFAs can decrease cytokine release in response to LPS. These in vitro experiments suggest that sEH inhibition, through preservation of epFAs like those tested here, may act to reduce the chronic inflammation associated with EtOH consumption by acting on both hepatocytes, to prevent cell death, and macrophages, to prevent the release of inflammatory mediators.

While these results suggest a pathogenic role for sEH in ALD and t-TUCB as a potential therapeutic, this study is not without its limitations. First, the t-TUCB drug administration paradigm used here was preventative, meaning the inhibitor was given throughout the duration of the study. A previous non-alcoholic liver disease study used a treatment paradigm where the sEHI was administered after establishing liver injury and 
still showed significant protection [40], meaning both paradigms may be efficacious. Our future work will address whether treatment with t-TUCB after EtOH-induced liver injury is established can still attenuate liver injury, inflammation, and ER stress. Second, we used whole-body sEH knockout mice to validate our results with t-TUCB in a genetic model. sEH knockout mice lack expression of both the C-terminal hydrolase domain and the $\mathrm{N}$ terminal phosphatase domain. Therefore, it is impossible to determine whether any effects we observed in sEH knockout mice were due to a lack of hydrolase activity, phosphatase activity, or both. The biological role of the phosphatase activity remains largely unknown, although in vitro studies have demonstrated that lipids such as farsenyl pyrophosphate, sphingosine-1-phosphate, and lysophosphatidic acid act as substrates [123-125]. These lipid phosphates are involved in cell signaling, growth, and survival, and act as components of the cell membrane [125]. Lysophosphatidic acid, further, has been implicated in the development of liver fibrosis and liver cancer [126, 127]. Efforts to develop phosphatase domain inhibitors have recently begun [128]; our future work will aim to investigate this domain in the context of ALD using these compounds. In future research we will also consider using liver-specific sEH knockout mice as opposed to whole-body knockout mice to study the effects of loss of sEH inhibition within the context of the liver alone. sEH is expressed is many tissues [129], meaning whole-body loss of sEH expression may have confounding effects through other organs. 


\section{CHAPTER 5}

\section{SUMMARY AND CONCLUSIONS}

sEH inhibition is a promising therapeutic strategy for the treatment of numerous diseases, including early-stage liver diseases like simple steatosis and end-stage liver diseases like cirrhosis and sepsis. Our work suggests that ALD is another candidate liver disease that may benefit from sEH inhibition, given that human ALD patients had decreased liver epFAs and increased liver EPHX2 expression. A commonly used sEHI, tTUCB, prevented liver injury, inflammation, and ER stress in chronic and acute-on-chronic EtOH administration mouse models of ALD. In vitro, several epoxides derived from omega-3 PUFAs prevented hepatocyte cell death and expression of pro-inflammatory cytokines in macrophages. Continued research to evaluate sEH inhibition in ALD with tTUCB administered in a treatment paradigm as well as investigation of the $\mathrm{N}$-terminus phosphatase domain of sEH will help promote translation of sEH inhibition to the clinic in the near future (Figure 13). 


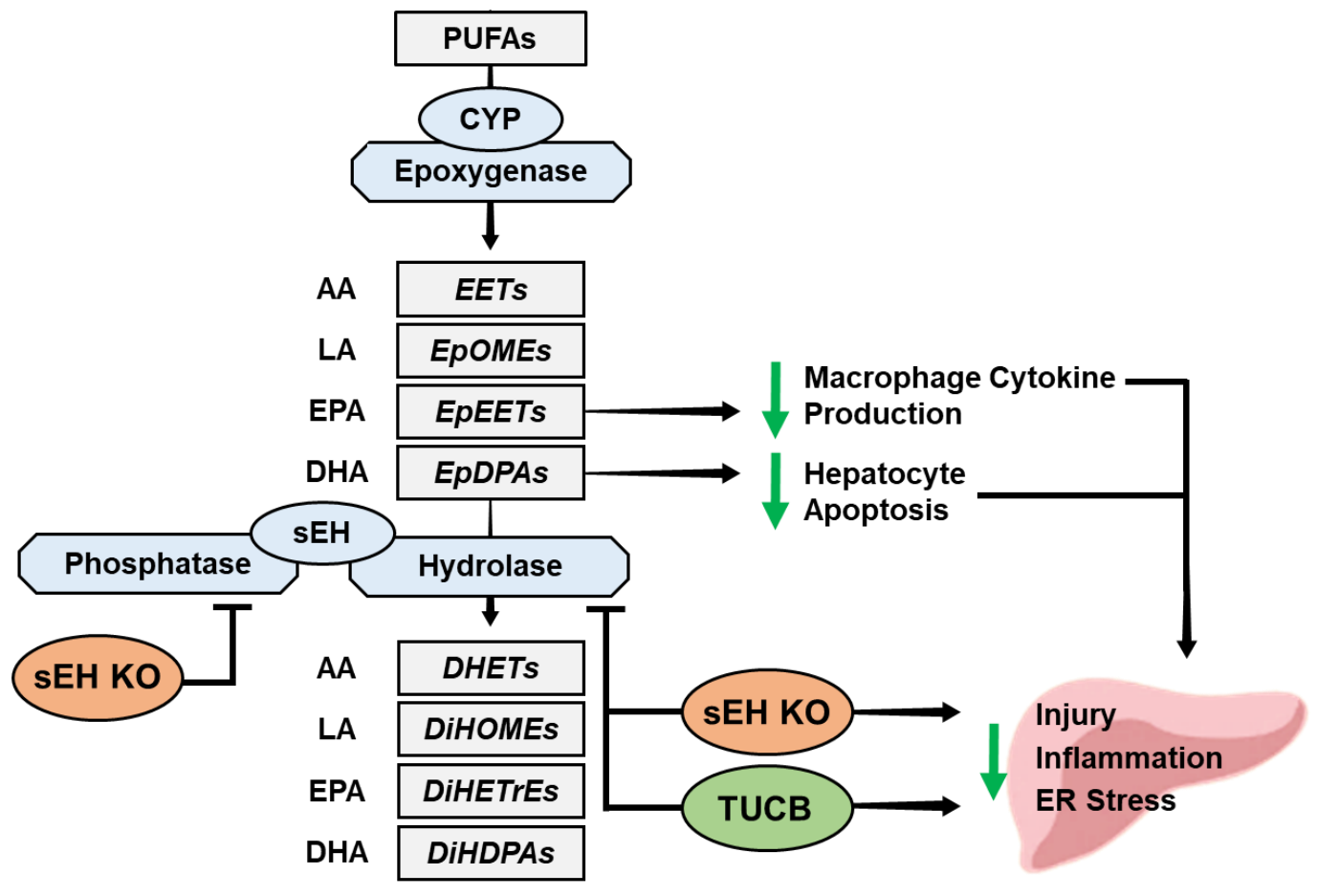

Figure 13. Summary figure. In vivo, the sEHI, t-TUCB, improved liver injury, inflammation, and ER stress associated with chronic or chronic-binge administration of EtOH in mouse models of ALD. Genetic ablation of sEH, which abrogates activity of both domains of sEH, similarly decreased liver injury and inflammation in a chronic-binge EtOH administration mouse model. In vitro, individual epFAs prevented hepatocyte cell death and macrophage-mediated pro-inflammatory cytokine release, potential contributors to the in vivo phenotype observed with t-TUCB. PUFAs, polyunsaturated fatty acids; CYP, cytochrome P450 2J/2C families; EET, epoxyeicosatrienoic acid; EpOME, epoxyoctadecenoic acid; EpEET, epoxyeicosatetraenoic acid; EpDPA, epoxydocosapentaenoic acid; DiHETE, dihydroxyeicosatrienoic acid; DiHOME, dihydroxyoctadecenoic acid; DiHETrE, dihydroxyeicosatetraenoic acid; DiHDPA, dihydoxydocosapentaenoic acid; sEH, soluble epoxide hydrolase; t-TUCB, 4-[[trans-4[[[[4-Trifluoromethoxy) phenyl] amino] carbonyl]-amino] cyclohexyl] oxy]-benzoic.

\section{Funding}

This work was supported by the following grants: National Institutes of Health grants R01 AA024102-01A1 (IAK), U01AA022489 (CJM), 1U01AA021901-01 (CJM), 1U01AA021893-01 (CJM), R01AA023681 (CJM), P30GM106396, the Department of Veterans Affairs I01BX000350 (CJM), and the Intramural Programs of the National 
Institute on Alcohol Abuse and Alcoholism. This work was also supported by an Institutional Development Award (IDeA) from the National Institute of General Medical Sciences of the National Institutes of Health under grant number P20GM113226 (CJM), and the National Institute on Alcohol Abuse and Alcoholism of the National Institutes of Health under Award Number P50AA024337 (CJM). The content is solely the responsibility of the authors and does not necessarily represent the official views of the National Institutes of Health. 


\section{REFERENCES}

1. Morisseau, C. and B.D. Hammock, Impact of soluble epoxide hydrolase and epoxyeicosanoids on human health. Annu Rev Pharmacol Toxicol, 2013. 53: p. 3758.

2. Brooks, G.T., A. Harrison, and S.E. Lewis, Cyclodiene epoxide ring hydration by microsomes from mammalian liver and houseflies. Biochem Pharmacol, 1970. 19(1): p. 255-73.

3. Beetham, J.K., et al., Gene evolution of epoxide hydrolases and recommended nomenclature. DNA Cell Biol, 1995. 14(1): p. 61-71.

4. Harris, T.R., et al., Identification of two epoxide hydrolases in Caenorhabditis elegans that metabolize mammalian lipid signaling molecules. Arch Biochem Biophys, 2008. 472(2): p. 139-49.

5. Sun, P., et al., Characterization of an epoxide hydrolase from the Florida red tide dinoflagellate, Karenia brevis. Phytochemistry, 2016. 122: p. 11-21.

6. van Loo, B., et al., Diversity and biocatalytic potential of epoxide hydrolases identified by genome analysis. Appl Environ Microbiol, 2006. 72(4): p. 2905-17.

7. Zeldin, D.C., Epoxygenase pathways of arachidonic acid metabolism. J Biol Chem, 2001. 276(39): p. 36059-62.

8. Node, K., et al., Anti-inflammatory properties of cytochrome P450 epoxygenasederived eicosanoids. Science, 1999. 285(5431): p. 1276-9.

9. Morin, C., et al., EET displays anti-inflammatory effects in TNF-alpha stimulated human bronchi: putative role of CPI-17. Am J Respir Cell Mol Biol, 2008. 38(2): p. 192-201.

10. Morin, C., et al., 17,18-epoxyeicosatetraenoic acid targets PPARgamma and p38 mitogen-activated protein kinase to mediate its anti-inflammatory effects in the lung: role of soluble epoxide hydrolase. Am J Respir Cell Mol Biol, 2010. 43(5): p. 564-75.

11. Imig, J.D., Epoxyeicosanoids in hypertension. Physiol Res, 2019. 68(5): p. 695704.

12. Gilroy, D.W., et al., CYP450-derived oxylipins mediate inflammatory resolution. Proc Natl Acad Sci U S A, 2016. 113(23): p. E3240-9.

13. Panigrahy, D., et al., Epoxyeicosanoids promote organ and tissue regeneration. Proc Natl Acad Sci U S A, 2013. 110(33): p. 13528-33.

14. Thompson, D.A. and B.D. Hammock, Dihydroxyoctadecamonoenoate esters inhibit the neutrophil respiratory burst. J Biosci, 2007. 32(2): p. 279-91.

15. Spector, A.A., Arachidonic acid cytochrome P450 epoxygenase pathway. J Lipid Res, 2009. 50 Suppl: p. S52-6.

16. Kramer, J. and E. Proschak, Phosphatase activity of soluble epoxide hydrolase. Prostaglandins Other Lipid Mediat, 2017. 133: p. 88-92.

17. Moghaddam, M.F., et al., Bioactivation of leukotoxins to their toxic diols by epoxide hydrolase. Nat Med, 1997. 3(5): p. 562-6.

18. Lee, K.S., et al., Optimized inhibitors of soluble epoxide hydrolase improve in vitro target residence time and in vivo efficacy. J Med Chem, 2014. 57(16): p. 7016-30. 
19. Li, D., et al., Inhibition of soluble epoxide hydrolase alleviated atherosclerosis by reducing monocyte infiltration in Ldlr(-/-) mice. J Mol Cell Cardiol, 2016. 98: p. 128-37.

20. Gurung, A.B., B. Mayengbam, and A. Bhattacharjee, Discovery of novel drug candidates for inhibition of soluble epoxide hydrolase of arachidonic acid cascade pathway implicated in atherosclerosis. Comput Biol Chem, 2018. 74: p. 1-11.

21. Bettaieb, A., et al., Podocyte-specific soluble epoxide hydrolase deficiency in mice attenuates acute kidney injury. FEBS J, 2017. 284(13): p. 1970-1986.

22. Klocke, J., et al., Prophylactic inhibition of soluble epoxide hydrolase delays onset of nephritis and ameliorates kidney damage in NZB/W F1 mice. Sci Rep, 2019. 9(1): p. 8993.

23. Chiang, C.W., et al., Genetic deletion of soluble epoxide hydrolase attenuates inflammation and fibrosis in experimental obstructive nephropathy. Mediators Inflamm, 2015. 2015: p. 693260.

24. Lee, J.P., et al., Soluble epoxide hydrolase activity determines the severity of ischemia-reperfusion injury in kidney. PLoS One, 2012. 7(5): p. e37075.

25. Li, P.S., et al., Effect of Soluble Epoxide Hydrolase in Hyperoxic Acute Lung Injury in Mice. Inflammation, 2018. 41(3): p. 1065-1072.

26. Tao, W., et al., Effects of a Soluble Epoxide Hydrolase Inhibitor on Lipopolysaccharide-Induced Acute Lung Injury in Mice. PLoS One, 2016. 11(8): p. e0160359.

27. Liu, L.P., et al., Deletion of soluble epoxide hydrolase attenuates mice Hyperoxic acute lung injury. BMC Anesthesiol, 2018. 18(1): p. 48.

28. Zhou, Y., et al., Soluble Epoxide Hydrolase Inhibitor Attenuates Lipopolysaccharide-Induced Acute Lung Injury and Improves Survival in Mice. Shock, 2017. 47(5): p. 638-645.

29. Wang, W., et al., Lipidomic profiling reveals soluble epoxide hydrolase as a therapeutic target of obesity-induced colonic inflammation. Proc Natl Acad Sci U S A, 2018. 115(20): p. 5283-5288.

30. Zhang, W., et al., Soluble epoxide hydrolase gene deficiency or inhibition attenuates chronic active inflammatory bowel disease in IL-10(-/-) mice. Dig Dis Sci, 2012. 57(10): p. 2580-91.

31. Reisdorf, W.C., et al., Preclinical evaluation of EPHX2 inhibition as a novel treatment for inflammatory bowel disease. PLoS One, 2019. 14(4): p. e0215033.

32. Zhang, G., S. Kodani, and B.D. Hammock, Stabilized epoxygenated fatty acids regulate inflammation, pain, angiogenesis and cancer. Prog Lipid Res, 2014. 53: p. 108-23.

33. Xia, R., et al., Inhibition of Pancreatic Carcinoma Growth Through Enhancing omega-3 Epoxy Polyunsaturated Fatty Acid Profile by Inhibition of Soluble Epoxide Hydrolase. Anticancer Res, 2019. 39(7): p. 3651-3660.

34. $\mathrm{Wu}, \mathrm{Q}$, , et al., The effects of $\mathrm{SEH}$ inhibitor on depression-like behavior and neurogenesis in male mice. J Neurosci Res, 2017. 95(12): p. 2483-2492.

35. Hashimoto, K., Role of Soluble Epoxide Hydrolase in Metabolism of PUFAs in Psychiatric and Neurological Disorders. Front Pharmacol, 2019. 10: p. 36.

36. Ren, Q., Soluble Epoxide Hydrolase Inhibitor: A Novel Potential Therapeutic or Prophylactic Drug for Psychiatric Disorders. Front Pharmacol, 2019. 10: p. 420. 
37. Hashimoto, K., Soluble epoxide hydrolase: a new therapeutic target for depression. Expert Opin Ther Targets, 2016. 20(10): p. 1149-51.

38. Chen, Z., et al., sEH Inhibitor TPPU Ameliorates Cecal Ligation and PunctureInduced Sepsis by Regulating Macrophage Functions. Shock, 2019.

39. Yang, L., et al., Mechanisms of Vascular Dysfunction in COPD and Effects of a Novel Soluble Epoxide Hydrolase Inhibitor in Smokers. Chest, 2017. 151(3): p. 555-563.

40. Liu, Y., et al., Inhibition of soluble epoxide hydrolase attenuates high-fat-dietinduced hepatic steatosis by reduced systemic inflammatory status in mice. PLoS One, 2012. 7(6): p. e39165.

41. Bettaieb, A., et al., Soluble epoxide hydrolase deficiency or inhibition attenuates diet-induced endoplasmic reticulum stress in liver and adipose tissue. $\mathrm{J} \mathrm{Biol} \mathrm{Chem}$, 2013. 288(20): p. 14189-99.

42. Lopez-Vicario, C., et al., Inhibition of soluble epoxide hydrolase modulates inflammation and autophagy in obese adipose tissue and liver: role for omega-3 epoxides. Proc Natl Acad Sci U S A, 2015. 112(2): p. 536-41.

43. Sun, C.C., et al., PTUPB ameliorates high-fat diet-induced non-alcoholic fatty liver disease via inhibiting NLRP3 inflammasome activation in mice. Biochem Biophys Res Commun, 2020. 523(4): p. 1020-1026.

44. Zhang, C.H., et al., Soluble epoxide hydrolase inhibition with t-TUCB alleviates liver fibrosis and portal pressure in carbon tetrachloride-induced cirrhosis in rats. Clin Res Hepatol Gastroenterol, 2018. 42(2): p. 118-125.

45. Younossi, Z.M., et al., Global epidemiology of nonalcoholic fatty liver diseaseMeta-analytic assessment of prevalence, incidence, and outcomes. Hepatology, 2016. 64(1): p. 73-84.

46. Lazaar, A.L., et al., Pharmacokinetics, pharmacodynamics and adverse event profile of GSK2256294, a novel soluble epoxide hydrolase inhibitor. Br J Clin Pharmacol, 2016. 81(5): p. 971-9.

47. Iyer, A., et al., Pharmacological inhibition of soluble epoxide hydrolase ameliorates diet-induced metabolic syndrome in rats. Exp Diabetes Res, 2012. 2012: p. 758614.

48. Chen, G., et al., CYP2J2 overexpression attenuates nonalcoholic fatty liver disease induced by high-fat diet in mice. Am J Physiol Endocrinol Metab, 2015. 308(2): p. E97-E110.

49. Yao, L., et al., Inhibition of soluble epoxide hydrolase ameliorates hyperhomocysteinemia-induced hepatic steatosis by enhancing beta-oxidation of fatty acid in mice. Am J Physiol Gastrointest Liver Physiol, 2019. 316(4): p. G527G538.

50. Mangels, N., et al., The soluble epoxide hydrolase determines cholesterol homeostasis by regulating AMPK and SREBP activity. Prostaglandins Other Lipid Mediat, 2016. 125: p. 30-9.

51. Harris, T.R., et al., Inhibition of soluble epoxide hydrolase attenuates hepatic fibrosis and endoplasmic reticulum stress induced by carbon tetrachloride in mice. Toxicol Appl Pharmacol, 2015. 286(2): p. 102-11. 
52. Deng, W., et al., Inhibition of soluble epoxide hydrolase lowers portal hypertension in cirrhotic rats by ameliorating endothelial dysfunction and liver fibrosis. Prostaglandins Other Lipid Mediat, 2017. 131: p. 67-74.

53. Fife, K.L., et al., Inhibition of soluble epoxide hydrolase does not protect against endotoxin-mediated hepatic inflammation. J Pharmacol Exp Ther, 2008. 327(3): p. 707-15.

54. Paschos, P. and K. Paletas, Non alcoholic fatty liver disease and metabolic syndrome. Hippokratia, 2009. 13(1): p. 9-19.

55. Maurice, J. and P. Manousou, Non-alcoholic fatty liver disease. Clin Med (Lond), 2018. 18(3): p. 245-250.

56. Neuschwander-Tetri, B.A., Non-alcoholic fatty liver disease. BMC Med, 2017. 15(1): p. 45.

57. Hagstrom, H., et al., Steatohepatitis Is Not Associated with an Increased Risk for Fibrosis Progression in Nonalcoholic Fatty Liver Disease. Gastroenterol Res Pract, 2018. 2018: p. 1942648.

58. Armstrong, M.J., et al., Extrahepatic complications of nonalcoholic fatty liver disease. Hepatology, 2014. 59(3): p. 1174-97.

59. Yao, L., et al., Hyperhomocysteinemia activates the aryl hydrocarbon receptor/CD36 pathway to promote hepatic steatosis in mice. Hepatology, 2016. 64(1): p. 92-105.

60. Dai, H., et al., Association between homocysteine and non-alcoholic fatty liver disease in Chinese adults: a cross-sectional study. Nutr J, 2016. 15(1): p. 102.

61. Luan, J. and D. Ju, Inflammasome: A Double-Edged Sword in Liver Diseases. Front Immunol, 2018. 9: p. 2201.

62. Henkel, A. and R.M. Green, The unfolded protein response in fatty liver disease. Semin Liver Dis, 2013. 33(4): p. 321-9.

63. Lebeaupin, C., et al., Endoplasmic reticulum stress signalling and the pathogenesis of non-alcoholic fatty liver disease. J Hepatol, 2018. 69(4): p. 927-947.

64. Ueno, T. and M. Komatsu, Autophagy in the liver: functions in health and disease. Nat Rev Gastroenterol Hepatol, 2017. 14(3): p. 170-184.

65. Grumati, P., I. Dikic, and A. Stolz, ER-phagy at a glance. J Cell Sci, 2018. 131(17).

66. Schneider, J.L. and A.M. Cuervo, Liver autophagy: much more than just taking out the trash. Nat Rev Gastroenterol Hepatol, 2014. 11(3): p. 187-200.

67. Kisseleva, T. and D.A. Brenner, Mechanisms of fibrogenesis. Exp Biol Med (Maywood), 2008. 233(2): p. 109-22.

68. Iwaisako, K., et al., Origin of myofibroblasts in the fibrotic liver in mice. Proc Natl Acad Sci U S A, 2014. 111(32): p. E3297-305.

69. El-Swefy, S. and S.I. Hassanen, Improvement of hepatic fibrosis by leukotriene inhibition in cholestatic rats. Ann Hepatol, 2009. 8(1): p. 41-9.

70. Kim, S.M., et al., Effect of selective cyclooxygenase-2 inhibitor meloxicam on liver fibrosis in rats with ligated common bile ducts. Hepatol Res, 2008. 38(8): p. 8009.

71. Node, K., et al., Activation of Galpha s mediates induction of tissue-type plasminogen activator gene transcription by epoxyeicosatrienoic acids. J Biol Chem, 2001. 276(19): p. 15983-9. 
72. Gracia-Sancho, J. and W. Laleman, Mechanisms of portal hypertension: Bench to bedside. Clin Liver Dis (Hoboken), 2016. 8(6): p. 160-166.

73. Rockey, D.C. and J.J. Chung, Reduced nitric oxide production by endothelial cells in cirrhotic rat liver: endothelial dysfunction in portal hypertension. Gastroenterology, 1998. 114(2): p. 344-51.

74. Hercule, H.C., et al., Interaction between P450 eicosanoids and nitric oxide in the control of arterial tone in mice. Arterioscler Thromb Vasc Biol, 2009. 29(1): p. 5460.

75. Gotts, J.E. and M.A. Matthay, Sepsis: pathophysiology and clinical management. BMJ, 2016. 353: p. i1585.

76. Fernandez, J., et al., Bacterial infections in cirrhosis: epidemiological changes with invasive procedures and norfloxacin prophylaxis. Hepatology, 2002. 35(1): p. 1408.

77. Borzio, M., et al., Bacterial infection in patients with advanced cirrhosis: a multicentre prospective study. Dig Liver Dis, 2001. 33(1): p. 41-8.

78. Schmelzer, K.R., et al., Soluble epoxide hydrolase is a therapeutic target for acute inflammation. Proc Natl Acad Sci U S A, 2005. 102(28): p. 9772-7.

79. Buras, J.A., B. Holzmann, and M. Sitkovsky, Animal models of sepsis: setting the stage. Nat Rev Drug Discov, 2005. 4(10): p. 854-65.

80. Wang, W., et al., Targeted Metabolomics Identifies the Cytochrome P450 Monooxygenase Eicosanoid Pathway as a Novel Therapeutic Target of Colon Tumorigenesis. Cancer Res, 2019. 79(8): p. 1822-1830.

81. Liu, Y., et al., The antiinflammatory effect of laminar flow: the role of PPARgamma, epoxyeicosatrienoic acids, and soluble epoxide hydrolase. Proc Natl Acad Sci U S A, 2005. 102(46): p. 16747-52.

82. Liss, K.H. and B.N. Finck, PPARs and nonalcoholic fatty liver disease. Biochimie, 2017. 136: p. 65-74.

83. $\mathrm{Xu}, \mathrm{D} . \mathrm{Y}$., et al., A potent soluble epoxide hydrolase inhibitor, $t$-AUCB, acts through PPARgamma to modulate the function of endothelial progenitor cells from patients with acute myocardial infarction. Int J Cardiol, 2013. 167(4): p. 1298-304.

84. Hildreth, K., et al., Soluble Epoxide Hydrolase Inhibitor t-AUCB Promotes Murine Brown Adipogenesis: Role of PPAR Gamma and PPAR Alpha (P21-069-19). Current Developments in Nutrition, 2019. 3(3).

85. Dai, N., et al., Vascular repair and anti-inflammatory effects of soluble epoxide hydrolase inhibitor. Exp Ther Med, 2019. 17(5): p. 3580-3588.

86. Fang, X., et al., 14,15-Dihydroxyeicosatrienoic acid activates peroxisome proliferator-activated receptor-alpha. Am J Physiol Heart Circ Physiol, 2006. 290(1): p. H55-63.

87. Fang, X., et al., Activation of peroxisome proliferator-activated receptor alpha by substituted urea-derived soluble epoxide hydrolase inhibitors. J Pharmacol Exp Ther, 2005. 314(1): p. 260-70.

88. Khadge, S., et al., Dietary omega-3 and omega-6 polyunsaturated fatty acids modulate hepatic pathology. J Nutr Biochem, 2018. 52: p. 92-102.

89. Lonardo, A., et al., Sex Differences in Nonalcoholic Fatty Liver Disease: State of the Art and Identification of Research Gaps. Hepatology, 2019. 70(4): p. 14571469. 
90. Koerner, I.P., et al., Soluble epoxide hydrolase: regulation by estrogen and role in the inflammatory response to cerebral ischemia. Front Biosci, 2008. 13: p. 283341.

91. Yang, Y.M., et al., Estrogen-dependent epigenetic regulation of soluble epoxide hydrolase via DNA methylation. Proc Natl Acad Sci U S A, 2018. 115(3): p. 613618.

92. Huang, A. and D. Sun, Sexually Dimorphic Regulation of EET Synthesis and Metabolism: Roles of Estrogen. Front Pharmacol, 2018. 9: p. 1222.

93. Osna, N.A., T.M. Donohue, Jr., and K.K. Kharbanda, Alcoholic Liver Disease: Pathogenesis and Current Management. Alcohol Res, 2017. 38(2): p. 147-161.

94. Hirschfield, G.M., E.J. Heathcote, and M.E. Gershwin, Pathogenesis of cholestatic liver disease and therapeutic approaches. Gastroenterology, 2010. 139(5): p. 148196.

95. Rocken, C. and S. Carl-McGrath, Pathology and pathogenesis of hepatocellular carcinoma. Dig Dis, 2001. 19(4): p. 269-78.

96. Przybyla-Zawislak, B.D., et al., Polymorphisms in human soluble epoxide hydrolase. Mol Pharmacol, 2003. 64(2): p. 482-90.

97. Morisseau, C., et al., Effect of soluble epoxide hydrolase polymorphism on substrate and inhibitor selectivity and dimer formation. J Lipid Res, 2014. 55(6): p. 1131-8.

98. Ramirez, C.E., et al., Arg287Gln variant of EPHX2 and epoxyeicosatrienoic acids are associated with insulin sensitivity in humans. Prostaglandins Other Lipid Mediat, 2014. 113-115: p. 38-44.

99. Fornage, M., et al., Polymorphism of the soluble epoxide hydrolase is associated with coronary artery calcification in African-American subjects: The Coronary Artery Risk Development in Young Adults (CARDIA) study. Circulation, 2004. 109(3): p. 335-9.

100. Lee, C.R., et al., Genetic variation in soluble epoxide hydrolase (EPHX2) is associated with forearm vasodilator responses in humans. Hypertension, 2011. 57(1): p. 116-22.

101. Gao, B. and R. Bataller, Alcoholic liver disease: pathogenesis and new therapeutic targets. Gastroenterology, 2011. 141(5): p. 1572-85.

102. Farooq, M.O. and R. Bataller, Pathogenesis and Management of Alcoholic Liver Disease. Dig Dis, 2016. 34(4): p. 347-55.

103. Dara, L., C. Ji, and N. Kaplowitz, The contribution of endoplasmic reticulum stress to liver diseases. Hepatology, 2011. 53(5): p. 1752-63.

104. Livak, K.J. and T.D. Schmittgen, Analysis of relative gene expression data using real-time quantitative PCR and the 2(-Delta Delta C(T)) Method. Methods, 2001. 25(4): p. 402-8.

105. Tsuru, A., et al., Novel mechanism of enhancing IRElalpha-XBP1 signalling via the PERK-ATF4 pathway. Sci Rep, 2016. 6: p. 24217.

106. Bradford, M.M., A rapid and sensitive method for the quantitation of microgram quantities of protein utilizing the principle of protein-dye binding. Anal Biochem, 1976. 72: p. 248-54. 
107. Kirpich, I.A., et al., Integrated hepatic transcriptome and proteome analysis of mice with high-fat diet-induced nonalcoholic fatty liver disease. J Nutr Biochem, 2011. 22(1): p. 38-45.

108. Warner, D.R., et al., Ethanol and unsaturated dietary fat induce unique patterns of hepatic omega-6 and omega-3 PUFA oxylipins in a mouse model of alcoholic liver disease. PLoS One, 2018. 13(9): p. e0204119.

109. Wang, M., et al., Chronic alcohol ingestion modulates hepatic macrophage populations and functions in mice. J Leukoc Biol, 2014. 96(4): p. 657-65.

110. Bertola, A., et al., Mouse model of chronic and binge ethanol feeding (the NIAAA model). Nat Protoc, 2013. 8(3): p. 627-37.

111. Ji, C., et al., Role of CHOP in hepatic apoptosis in the murine model of intragastric ethanol feeding. Alcohol Clin Exp Res, 2005. 29(8): p. 1496-503.

112. Gao, B. and H. Tsukamoto, Inflammation in Alcoholic and Nonalcoholic Fatty Liver Disease: Friend or Foe? Gastroenterology, 2016. 150(8): p. 1704-9.

113. Lamas-Paz, A., et al., Alcoholic liver disease: Utility of animal models. World J Gastroenterol, 2018. 24(45): p. 5063-5075.

114. Jaeschke, H., Neutrophil-mediated tissue injury in alcoholic hepatitis. Alcohol, 2002. 27(1): p. 23-7.

115. Rasineni, K. and C.A. Casey, Molecular mechanism of alcoholic fatty liver. Indian J Pharmacol, 2012. 44(3): p. 299-303.

116. Ji, C., Dissection of endoplasmic reticulum stress signaling in alcoholic and nonalcoholic liver injury. J Gastroenterol Hepatol, 2008. 23 Suppl 1: p. S16-24.

117. Baiceanu, A., et al., Endoplasmic reticulum proteostasis in hepatic steatosis. Nat Rev Endocrinol, 2016. 12(12): p. 710-722.

118. Sha, H., et al., The IRElalpha-XBP1 pathway of the unfolded protein response is required for adipogenesis. Cell Metab, 2009. 9(6): p. 556-64.

119. Natori, S., et al., Hepatocyte apoptosis is a pathologic feature of human alcoholic hepatitis. J Hepatol, 2001. 34(2): p. 248-53.

120. Rao, R., Endotoxemia and gut barrier dysfunction in alcoholic liver disease. Hepatology, 2009. 50(2): p. 638-44.

121. Dixon, L.J., et al., Kupffer cells in the liver. Compr Physiol, 2013. 3(2): p. 785-97.

122. Li, P., et al., The role of Kupffer cells in hepatic diseases. Mol Immunol, 2017. 85: p. 222-229.

123. Tran, K.L., et al., Lipid sulfates and sulfonates are allosteric competitive inhibitors of the N-terminal phosphatase activity of the mammalian soluble epoxide hydrolase. Biochemistry, 2005. 44(36): p. 12179-87.

124. Morisseau, C., et al., Role of soluble epoxide hydrolase phosphatase activity in the metabolism of lysophosphatidic acids. Biochem Biophys Res Commun, 2012. 419(4): p. 796-800.

125. Oguro, A. and S. Imaoka, Lysophosphatidic acids are new substrates for the phosphatase domain of soluble epoxide hydrolase. J Lipid Res, 2012. 53(3): p. 50512.

126. Yang, F. and G.X. Chen, Production of extracellular lysophosphatidic acid in the regulation of adipocyte functions and liver fibrosis. World J Gastroenterol, 2018. 24(36): p. 4132-4151. 
127. Kaffe, E., C. Magkrioti, and V. Aidinis, Deregulated Lysophosphatidic Acid Metabolism and Signaling in Liver Cancer. Cancers (Basel), 2019. 11(11).

128. Kramer, J.S., et al., Discovery of the First in Vivo Active Inhibitors of the Soluble Epoxide Hydrolase Phosphatase Domain. J Med Chem, 2019. 62(18): p. 84438460.

129. Harris, T.R. and B.D. Hammock, Soluble epoxide hydrolase: gene structure, expression and deletion. Gene, 2013. 526(2): p. 61-74. 
Jeffrey B. Warner

1910 Rudy Lane, Louisville KY, 40207 | 502-807-3950 |

jeff.warner01@gmail.com

\section{Education}

University of Louisville

2018 - Present

Department of Pharmacology and Toxicology

PhD Student

Cumulative GPA 3.971/4.0

Murray State University, Murray KY

2017

B.S., Pre-Medicine/Biology (Major)

Chemistry (Minor)

Honors Diploma, summa cum laude

GPA: 3.91/4.0

DuPont Manual High School, Louisville KY

2013

Math, Science, \& Technology Magnet

GPA: 3.99/4.0

8 Advanced Placement Courses (45 Credit Hours)

\section{Experience}

Research Technician

May 2017 - July 2018

University of Louisville School of Medicine

Department of Gastroenterology, Hepatology, \& Nutrition

Responsibilities: conduct experiments related to the investigation of the link between fatty acid metabolism $\&$ alcoholic liver disease pathogenesis, compile data, and prepare written and oral reports

Research Technician May 2012 - August 2013

University of Louisville Birth Defects Center

Department of Molecular, Cellular, \& Craniofacial Biology

School of Dentistry 
Responsibilities: genotyping, cell culture, laboratory maintenance

\section{Awards and Honors}

1. Travel Award, National Institutes of Health/National Institute of Environmental Health Sciences, Experimental Biology Annual Meeting, April 21-26. San Diego, CA, USA

2. ISALPD/C Travel award - International Society for Biomedical Research on Alcoholism Congress 2018, Kyoto, Japan, September 9-13, 2018

3. UofL Graduate School Council Travel award - Experimental Biology Meeting 2019, Orlando, Florida, April 6-10, 2019

4. American Society for Biochemistry and Molecular Biology Travel Award Experimental Biology Meeting, San Diego, CA, USA, April 4-7th, 2020

5. Research! Louisville 2019 - 1st Place, Master's Students Category

6. 2019 University of Louisville Graduate Student Regional Research Conference 1st Place, Afternoon Poster Session

\section{Scientific Outreach}

1. 2020 Louisville Regional Science and Engineering Fair - Judge

\section{Grants}

1. Type: T32 Institutional Training Grant (5T32ES011564-15); Agency: National Institutes of Health; Funding Period: 07/01/20 - 06/30/21

\section{Publications}

Honors Thesis

Warner, Jeffrey B., "Risk Assessment in CRISPR Transgenic Organisms" (2017). Honors College Theses. 11.

http://digitalcommons.murraystate.edu/honorstheses/11

Peer-Reviewed Publications 
1. Dastidar, S Gosh; Warner, JB; Warner, DR; McClain, CJ; Kirpich, IA. Rodent Models of Alcoholic Liver Disease: Role of Binge Ethanol Administration. Biomolecules, 2018; 8(1):3. Doi:10.3390/biom8010003

2. D.R. Warner, H. Liu, S. Ghosh Dastidar, J.B. Warner, M.A.I. Prodhan, X. Yin, X. Zhang, A.E. Feldstein, B. Gao, R.A. Prough, C.J. McClain, I.A. Kirpich. (2018) PLOS One "Ethanol and unsaturated dietary fat induce unique patterns of hepatic $\omega-6$ and $\omega-3$ PUFA oxylipins in a mouse model of alcoholic liver disease".

3. Zirnheld, KH; Warner, DR; Warner, JB; Hardesty, JE; McClain, CJ; Kirpich, IA. "Dietary Fatty Acids and Bioactive Fatty Acid Metabolites in Alcoholic Liver Disease.” Liver Research, vol. 3, no. 3-4, Elsevier BV, Dec. 2019, pp. 206-17.

4. Warner, DR; Warner, JB; Hardesty, JE; Song, YL; King, TN; Kang, JX; Chen, CY; Xie, S; Yuan, F; Prodhan, MAI; Ma, X; Zhang, X; Rouchka, EC; Maddipati, KR; Whitlock, J; Li, EC; Wang, GP; McClain, CJ; Kirpich, IA. "Decreased n6/n3 PUFA ratio attenuates ethanol-induced alterations in intestinal homeostasis, microbiota and liver injury." Journal of Lipid Research, vol. 60, no.12, Oct. 2019, pp. 2034-49.

5. Warner, J.; Hardesty, J.; Zirnheld, K.; McClain, C.; Warner, D.; Kirpich, I. Soluble Epoxide Hydrolase Inhibition in Liver Diseases: A Review of Current Research and Knowledge Gaps. Biology 2020, 9, 124.

\section{Presentations (Abstracts)}

1. S.G. Dastidar, D.R. Warner, Y.Song, J.B. Warner, G.E. Arteel, C.J. McClain, I.A. Kirpich. Omega-3 fatty acids and their resolvin metabolites attenuated hepatic liver injury in a mouse model of alcoholic liver disease Ohio Valley Society of Toxicology Meeting. July 14, 2017, Louisville, KY.

2. Warner, JB; Warner, DR; Howell, M; Chen, C; Hibbeln, J; McClain, CJ; Kirpich, IA. Lowering dietary n6/n3 Ratio Attenuated Liver Injury and Down-Regulated Hepatic Pro-Inflammatory Cytokine MIP2- $\alpha$ in Mice Exposed to a Binge Ethanol Administration. Research! Louisville 2017.

3. Warner, DR; Song, YL; Dastidar, SG; Warner, JB; McClain, CJ; Kirpich, IA. Endogenous increase in $\omega-3$ polyunsaturated fatty acids or the metabolite, resolvin D1, attenuates liver injury resulting from chronic alcohol consumption in mice. Research! Louisville 2017. 
4. S. Ghosh-Dastidar, D.R. Warner, Y.Song, J.B. Warner, G.E. Arteel, C.J. McClain, I.A. Kirpich. Resolvin D1 markedly attenuated ethanol and LPS-induced liver injury by reducing the hepatic pro-inflammatory response in mice. American Association for the study of liver disease (AASLD) meeting. October 20-24, 2017. Washington DC, USA. Hepatology, 2017:66(1s):694A-695A (1290).

5. D.R. Warner, S.Ghosh Dastidar, Y.L. Song, J.B. Warner, C.J. McClain, I.A. Kirpich. Mice with endogenously elevated $\omega-3$ polyunsaturated fatty acids have attenuated liver injury induced by chronic alcohol administration. American Association for the study of liver disease (AASLD) meeting. October 20-24, 2017. Washington DC, USA. AASLD Presidential Poster of Distinction Award. Hepatology, 2017:66(1s):688A (1277).

6. D.R. Warner, V.Vatsalya, S.Ghosh Dastidar, J.B. Warner, C.J. McClain, I.A. Kirpich. Low levels of resolvin D1 in severe alcoholic hepatitis: potential mechanisms and new therapy for alcoholic liver disease. Keystone Symposia «The role of resolution of inflammation in health and disease», March 24-28, 2018. Dublin, Ireland.

7. S.Ghosh Dastidar, D.R. Warner, J.B. Warner, C.J. McClain, I.A. Kirpich. Resolvin D1 markedly attenuated ethanol and LPS-induced liver injury in mice by decreasing hepatic pro-inflammatory response via inhibition of inflammasome activation. Keystone Symposia «The role of resolution of inflammation in health and disease», March 24-28, 2018. Dublin, Ireland.

8. J.B. Warner, S.Ghosh Dastidar, D.R. Warner, Y.Song, C.McClain, I.Kirpich. Inhibition of Soluble Epoxide Hydrolase by t-TUCB Ameliorated Liver Injury in a Chronic-Binge Ethanol Administration Mouse Model. Experimental Biology meeting, April 21-26, 2018. San Diego, CA, USA. Abstract \# C127 560.8. Recognition as an outstanding achievement at the Epoxide Hydrolase poster session \& Travel Grant Award from NIH/NIEHS.

9. S.Ghosh Dastidar, D.R. Warner, Y.L. Song, J.B. Warner, C.J. McClain, Irina A. Kirpich. Effect of Elevated $\omega-3 / \omega-6$ PUFA ratio on High-Fat Diet and Acute Ethanol-induced Obesity, Glucose Intolerance and Liver Injury in Mice. Experimental Biology meeting, April 21-26, 2018. San Diego, CA, USA. Abstract B531 812.39.

10. D.R. Warner, S.Ghosh Dastidar, Y.L. Song, J.B. Warner, C.J. McClain, I.A. Kirpich. Hepatic Gene Expression Changes in a Mouse Model of Alcoholic Liver Disease: Effect of the n-6:n-3 Polyunsaturated Fatty Acid Ratio. Experimental Biology meeting, April 21-26, 2018. San Diego, CA, USA. Poster of Distinction of the Gastrointestinal \& Liver Section of the APS. Abstract \# A603 760.5.

11. I.A. Kirpich, V.Vatsalya, D.R. Warner, S.Ghosh Dastidar, Y.Song, J.B. Warner, C.J. McClain. Low levels of $\omega-3$ PUFA metabolite, resolvin D1, in patients with 
severe alcoholic hepatitis: potential new therapeutic agent/strategy in the management of ALD. Poster of Distinction Award. Abstract rated in the top 10\% of all AASLD abstracts selected for poster presentation at DDW 2018. Washington DC, June 2-5, 2018.

12. S.Ghosh Dastidar, D.R. Warner, Y.Song, J.B. Warner, G.E. Arteel, C.J. McClain, I.A. Kirpich. Beneficial effect of resolvins in ethanol and LPS-induced liver injury via inhibition of pro-inflammatory gene expression and inflammasome activation Invited talk at the Clinical Symposium "NAFLD and NASH" DDW Meeting, Washington DC, June 2-5, 2018.

13. S.Ghosh Dastidar, D.R. Warner1, Y.Song, J.B. Warner, G.E. Arteel, C.J. McClain, I.A. Kirpich. Effects of resolvin D1 and E1 on systemic and hepatic inflammation caused by ethanol and LPS challenge: a time course analysis. AACC Meeting, Chicago, Il, July 29-August 2, 2018.

14. J.B. Warner, S. Ghost Dastidar, D.R. Warner, Y. Song, C.J. McClain, I.A. Kirpich. Inhibition of Soluble Epoxide Hydrolase Activity Attenuated Ethanol-Associated Liver Injury in Mice. Travel Grant Award. ISBRA Meeting, Kyoto, Japan, September 9-13, 2018.

15.D. Warner, S.Gosh Dastidar, Y.Song, J.B. Warner, J.Whitlock, E.C. Li, G.Wang, C.J. McClain, I.A. Kirpich Endogenous decrease in n-6/n-3 PUFA ratio modulates gut microbial dysbiosis and contributes to improvement of liver injury caused by ethanol and LPS administration in mice. ISBRA 2018 Congress, Kyoto, Japan, September 9-13, 2018. Alcoholism: Clinical and Experimental Research, 2018, 42(S2):p53A:abstract \#P2-5-5.

16.D.R. Warner, V.Vatsalya, S.Ghosh Dastidar, J.B. Warner, C.J. McClain, I.A. Kirpich Low levels of resolvin D1 in alcoholic hepatitis: potential mechanisms and new therapy for alcoholic liver disease. ISBRA 2018 Congress, Kyoto, Japan, September 9-14, 2018.

17.J.B. Warner, S.Ghosh Dastidar, D.R. Warner, Y.Song, C.J. McClain, I.A.Kirpich Misbalance of Epoxide and Diol Lipid Mediators in Alcoholic Liver Disease: Effects of Soluble Epoxide Hydrolase Inhibition in Experimental Mice. Research!Louisville, October 8-12, 2018. Louisville, KY, USA.

18. D.R. Warner, J.B. Warner, S.Ghosh Dastidar, Y.Song, J.Whitlock, E.C. Li, G.Wang, C.J. McClain, I.A.Kirpich The beneficial effects of the decreased tissue $\omega 6: \omega 3$ PUFA ratio on chronic ethanol and LPS associated liver injury are linked to the improvement of the intestinal homeostasis and modulation of the gut microbiota. American Association for the study of liver disease (AASLD) meeting. November 9-13, 2018. San Francisco, USA \# 0369 Hepatology, 2018, 68 (S1): 221. 
19. J.B. Warner, S.Ghosh Dastidar, D.R. Warner, Y.Song, C.J. McClain, I.A.Kirpich Imbalance of Epoxide and Diol Lipid Mediators in Alcoholic Liver Disease:Effects of Soluble Epoxide Hydrolase Inhibition in Experimental Mice. American Association for the study of liver disease (AASLD) meeting. November 9-13, 2018. San Francisco, USA \# 1424 Hepatology, 2018, 68 (S1): 816-817.

20. D.R. Warner, J.B. Warner, Y.Song, J.Whitlock, E.C. Li, G.Wang, C.J. McClain, I.A. Kirpich Critical Role for a $\omega 6: \omega 3$ PUFA Ratio in Shaping Responses of the Intestinal Mucosa and Microbiota to Ethanol and LPS Challenge: Implication for Alcoholic Liver Disease. Gordon Research Conference, Ventura, CA, March 2429, 2019.

21. J.B. Warner, D.R. Warner, Y. Song, C.J. McClain, I.A. Kirpich. Decrease of n6/n3 PUFA Ratio Augmented Growth and Improved Markers of Intestinal Barrier Integrity in Small Intestinal Organoids Derived from Naïve and Alcohol-Fed Mice. Experimental Biology meeting, Orlando, FL, April 6-9, 2019.

22. Hardesty JE, Warner JB, Warner DR, Jacobs JM, McClain CJ, Kirpich IA Proteomic and Phosphoproteomic Signatures of Severe Alcoholic Hepatitis. Experimental Biology meeting, April 6-9, 2019. Orlando, FL, USA. FASEB Journal, 2019, 33 (1S), Abstract 473.4.

23. D.R. Warner, J.B. Warner, Y.Song, J.Whitlock, E.C. Li, G.Wang, E.Rouchka, C.Chen, J.X. Kang, F.Yuan, X.Yin, X.Zhang, C.J. McClain, I.A. Kirpich Complementary Responses of the Intestinal Mucosa and Microbiota to Ethanol and LPS Challenge: Role of Endogenous Modulation of $\omega 6: \omega 3$ PUFA Ratio. Invited talk at the Topic Forum "Alcoholic liver disease: best of AGA and AASLD" DDW, San Diego, CA, May 18-21, 2019.

24. Warner, JB; Hardesty, JE; Song, YL; McClain, CJ; Kirpich, IA. Polyunsaturated fatty acid-derived epoxides improve alcoholic liver disease phenotype in cultured hepatocytes and macrophages. Research Society on Alcoholism Meeting, New Orleans LA, June 20-24, 2019.

25. D. R. Warner, J. B. Warner, Y. Song, J. Whitlock, E. C. Li, G. Wang, E. Rouchka, C. Chen, J. Hibbeln, C.J. McClain, and I.A. Kirpich Beneficial effects of lowering dietary or endogenous $\omega-6: \omega-3$ PUFA ratio on ethanol-mediated alterations in intestinal homeostasis, gut microbiome and liver injury. RSA, June 22-26, 2019. Minneapolis, MN. ACER, 2019, 43 (S1), p. 290A, Abstract 125.

26. J.B. Warner, D.R. Warner, Y.Song, C.J. McClain, I.A Kirpich Pharmacological inhibition of the metabolic pathway that converts epoxy- to dihydroxy-metabolites of omega- 6 and omega-3 fatty acids attenuated alcohol-induced liver injury in mice 
via reduction of ER stress. American Association for Clinical Chemistry (AACC), Anaheim, August 4-8, CA 2019.

27. D.R. Warner, J.B. Warner, Y.Song, C.J. McClain, I.A. Kirpich Decreased endogenous $\omega-6$ PUFAs induced intestinal mucosa transcriptional reprogramming that contributed to amelioration of intestinal and liver injury in mice in a setting of systemic inflammation and chronic ethanol exposure. American Association for Clinical Chemistry (AACC), Anaheim, August 4-8, CA 2019.

28. Warner, JB; Warner, DR; Song, YL; McClain, CJ; Kirpich, IA. Soluble Epoxide Hydrolase Inhibition: A Novel Therapeutic Strategy in Alcoholic Liver Disease. Research! Louisville, Louisville KY, September 10-13, 2019.

29.K. Zirnheld, V. Vatsalya, D.R. Warner, J.Warner, J.Hardesty, C.J. McClain, I.A. Kirpich Alterations in Bioactive Plasma Lipid Metabolites in Patients with Alcoholic Liver Disease: Associations with Disease Severity. Research!Louisville, Louisville, KY, USA. September 2019.

30. JE. Hardesty, JB. Warner, DR Warner, YLSong, CJ McClain, IA Kirpich Genetic ablation of $\mathrm{Fpr} 2$ in mice increased susceptibility to alcohol-mediated liver injury due to enhanced inflammation and impaired antimicrobial defense. Research!Louisville, Louisville, KY, USA. September 2019.

31. JB. Warner, YL. Song, DR. Warner, JE. Hardesty, CJ. McClain, IA. Kirpich Genetic Ablation or Pharmacological Inhibition of Soluble Epoxide Hydrolase Attenuated Liver Injury and Inflammation in Mouse Models of Alcoholic Liver Disease. American Association for the study of liver disease (AASLD) meeting. November 8-12, Boston, USA. Poster \# 1389; Hepatology, 2019, 70 (S1): 841A$842 \mathrm{~A}$.

32. JE. Hardesty, JB. Warner, DR. Warner, YSong, CJ. McClain, IA. Kirpich Fpr2-/mice are more susceptible to alcohol-induced liver injury due to impaired antimicrobial defense. American Association for the study of liver disease (AASLD) meeting. November 8-12, Boston, USA. Poster \# 285 Hepatology, 2019, 70 (S1):185A.

33. DR Warner, YL. Song, JB. Warner, CJ. McClain, IA. Kirpich Impaired Xenobiotic and Bile Acid Detoxification is Rescued by Reducing the Omega-6 to Omega-3 Polyunsaturated Fatty Acid Ratio in a Mouse Model of Alcoholic Liver Disease. American Association for the study of liver disease (AASLD) meeting. November 8-12, Boston, USA. Poster \# 1352; Hepatology, 2019, 70 (S1): 820A.

34. Warner, JB; Warner, DR; Hardesty, JE; Song, YL; McClain, CJ; Kirpich, IA. Soluble Epoxide Hydrolase Inhibition Attenuates Liver Injury in Experimental Alcoholic Liver Disease. First Integrated International Workshop on 
Acetyltransferases, Sulfotransferases, and UDP-Glucoronosyltransferases, Louisville KY, April 1-3, 2020 (postponed).

35.D.R. Warner, Y.L. Song, J.B. Warner, C.J. McClain, I.A. Kirpich Mice with endogenously increased $\omega$ PUFAs are resistant to alcohol-mediated downregulation of Wnt signaling. Experimental Biology meeting, San Diego, April 4-7, 2020. The FASEB Journal 34 (S1):1-1. Cancelled due to Covid-19.

36. J.B. Warner, J.E. Hardesty, D.R. Warner, Y.L. Song, C.J. McClain, I.A. Kirpich Effects of Dihydroxylated Fatty Acid Mediators on Liver Injury in a Mouse Model of Alcoholic Liver Disease. Experimental Biology meeting, San Diego, April 4-7, 2020. The FASEB Journal 34 (S1):1-1. Cancelled due to Covid-19.

37. J. Warner, I.S. Larsen, D.Warner, J. Hardesty, Y. Song, P. Nordkild, C. McClain, B. A. Holbech-Jensen, I. Kirpich Alcohol-induced liver injury is attenuated by human beta-defensin in experimental ALD via improvements in the gut-lived axis EASL, April 15-19, 2020, London, UK. Cancelled due to Covid-19.

38. J. Warner, I.S. Larsen, D.Warner, J. Hardesty, Y. Song, P. Nordkild, C. McClain, B. A. Holbech-Jensen, I. Kirpich Human beta defensin 2 as a potential beneficial agent to mitigate alcohol-induced alterations in the intestine and liver: multiple underlying mechanisms. DDW, May 2-5, 2020, Chicago, IL. Invited talk at the Plenary Session "Translational and Basic Discoveries". Cancelled due to Covid19.

39. D. Warner, V. Vatsalya, K. Zirnheld, J. Warner, J. Hardesty, S. Joshi Barve, C.J. McClain, I.A. Kirpich Elevated plasma 13-HODE is positively correlated with markers of systemic inflammation in patients at the early stage of alcoholassociated hepatitis. RSA, June 20-24, 2020 New Orleans, LA, USA. Cancelled due to Covid-19.

Manuscripts in Preparation

1. Warner, JB; Song, YL; Warner, DR; McClain, CJ; Kirpich, IA. Soluble Epoxide Hydrolase Inhibition Improves Outcomes in Mouse Models of Alcoholic Liver Disease. Manuscript in preparation.

2. Hardesty, JE*; Warner, JB*; Song, YL; Rouchka, EC; McClain, CJ; Warner, DR; Kirpich, IA. Transcriptional signatures of the small intestinal mucosa in response to ethanol and decreased tissue n6/n3 PUFA ratio in mice. Manuscript in review. *Equally contributing authors. 
3. Warner, DR; Warner JB; Hardesty, JE; Song, YL; McClain, CJ; Chen, CY; Kang, JX; Kirpich, IA. Beneficial effects of a decreased n6/n3 PUFA ratio on Wnt signaling was associated with attenuation of alcoholic liver disease in mice. Manuscript in revision.

4. Hardesty, JE; Warner, JB; Warner, DR; Song, YL; Kang, JX; Chen, CY; Xie, S; Rouchka, EC; McClain, CJ; Kirpich, IA. The effect of a decreased n6/n3 PUFA ratio on ethanol and LPS-mediated transcriptional signatures in the mouse small intestine. Manuscript in preparation. 